\title{
No Intolerance of Errors: The effect of Intolerance of Uncertainty on Performance Monitoring revisited
}

Marcelo Malbec*a , Joshua N. Hindmarsh*a, Joran Jongerling ${ }^{\mathrm{b}}$, Ingmar H. Franken ${ }^{\mathrm{a}}$, Matthias J. Wieser ${ }^{+\mathrm{a}}$

${ }^{\text {a }}$ Department of Psychology, Education, and Child Studies, Erasmus University Rotterdam, The Netherlands

${ }^{\mathrm{b}}$ Department of Methodology and Statistics, Tilburg University, The Netherlands

${ }^{+}$Corresponding author:

Matthias J. Wieser

Department of Psychology, Education and Child Studies, Erasmus University Rotterdam, P.O. 1738, 3000 DR Rotterdam, the Netherlands

Keywords (6):

Intolerance of Uncertainty, error monitoring, error-related negativity, Flanker task, EEG

* MM and JH contributed equally to this paper. 


\section{Highlights}

- Examined intolerance of uncertainty (IU), anxiety, depression, and error monitoring.

- No associations of IU and error-related negativity (ERN)

- No associations of subfactors of IU and ERN

- Failed replication despite large sample $(N=182)$ 


\begin{abstract}
Errors have been conceptualized as internal forms of threat that can cause harm in unpredictable ways. An index of error processing is the error-related negativity (ERN), an event-related potential reflecting variability in the sensitivity to errors. Prior work has shown the relationship between psychopathology symptoms and the ERN is unclear, and may be moderated by intolerance of uncertainty (IU), a trait that captures how people react to unpredictability. IU includes two subfactors of prospective IU (active seeking of predictability) and inhibitory IU (behavioral paralysis). In the present study, 182 undergraduates performed an Eriksen flanker task designed to elicit the ERN, while brain activity was recorded using electroencephalography (EEG). Participants completed the Intolerance of Uncertainty Scale, Short Form (IUS-12), and other measures of anxiety and depression. Total IU was not associated with the ERN in our sample, corroborating previous findings. However, in contrast to previous findings, the IU subfactors did also not predict the ERN or post-error slowing (PES), nor did total IU and depression interact to predict the ERN. Exploratory analyses also showed that total IU did not moderate the relationship between trait anxiety and the ERN. Small samples may have previously exaggerated the links between selfreported IU and the ERN. As such, further high-powered replications are required to confirm if, and how, they are related.
\end{abstract}




\section{Introduction}

\subsection{Error processing and psychopathology}

Errors are a vital source of information. Learning from our mistakes allows us to guide adaptive behaviors in response to a constantly changing environment. Error processing is part of a higher cognitive function called performance monitoring, which is the ability to scrutinize ongoing performance in order to detect, and therefore correct, mistakes (Dehaene et al., 1994). Despite the adaptive function of error processing, errors themselves have been conceptualized as forms of endogenous threat because their consequences can jeopardize wellbeing (Weinberg et al., 2016). Indeed, certain defensive physiological responses observed following errors (e.g., increased startle reflex and pupil dilation, changes in the skin conductance response, increased amygdala activity (Hajcak \& Foti, 2008; Hajcak et al., 2003; Pourtois et al., 2010) are similar to other exogenous types of threat, such as predators. However, unlike external threats, errors promote a uniquely interoceptive focus on one's behavior (Weinberg et al., 2016) and may be appraised more negatively by individuals at risk for internalizing psychopathology (Pasion \& Barbosa, 2019). Moreover, errors are inherently unpredictable (Proudfit et al., 2013) which means they may be particularly aversive to people who cannot tolerate the unexpected or unknown, regardless of psychopathology status.

An electrophysiological index of error detection is the error-related negativity (ERN), a negative deflection in the event-related potential (ERP) that occurs 50-100 ms after a person makes a mistake in a reaction-time task (Gehring et al., 1993). The ERN represents early and automatic registration of errors (Hoffmann \& Falkenstein, 2012) and functions as a signal for increased cognitive control and necessary behavioral adjustments (Weinberg et al., 2016). By contrast, more conscious and explicit processing of errors is indexed by the error positivity (Pe) which occurs 200-400 ms after error commission (Hewig et al., 2011). Enhanced ERNs have been observed in patients with obsessive-compulsive disorder (OCD; Endrass et al., 2008), generalized anxiety disorder (GAD; Weinberg et al., 2010) and social anxiety disorder (SAD; Endrass et al., 2008). While the ERN has been found to correlate with trait anxiety in non-clinical samples (Moser et al., 2013; Weinberg, Dieterich, et al., 2015), more recent meta-analytic work has found that the association between trait anxiety (as measured by the State-Trait Anxiety Inventory; Spielberger, 1983) and the ERN was smaller than previously assumed after correcting for publication bias (Saunders \& Inzlicht, 2020), with no overall correlation found between anxiety and the ERN across 29 non-clinical volunteer samples.

The relation between depression and the ERN is also unclear, with studies finding both enhanced (Weinberg et al., 2012) and diminished ERNs (Holmes \& Pizzagalli, 2008). 
One recent meta-analysis found no overall relationship between depression and ERN amplitude (Moran et al., 2017). Another meta-analysis found a negligible unique contribution of depression to the association between internalizing spectrum disorders and increased ERN (Pasion \& Barbosa, 2019). Indeed, depression has been found to obscure the relationship between GAD and the ERN, with the enhanced ERN found in those with a single GAD diagnosis not visible in comorbid subjects (i.e., GAD + depression; Weinberg, Kotov, et al., 2015). In short, the direct relationship between depression and the ERN appears weak at best. Findings suggesting weak associations between the ERN and symptoms are apparent even when considering symptoms at the transdiagnostic level (i.e., anxious-depression; Seow et al., 2020). These relationships might be more adequately explained by considering a potential underlying mechanism: variability in how people react to the unpredictability of threats.

\subsection{Intolerance of Uncertainty}

Intolerance of uncertainty (IU) is a dispositional tendency that reflects an individual's inability to endure ambiguous or uncertain events (Carleton, 2012, 2016; Freeston et al., 1994). These events are then perceived and interpreted as aversive and threatening (Dugas et al., 2005). IU is present in unselected samples, with higher levels associated with internalizing psychopathology, including GAD, SAD, OCD, panic disorder and depression (Mahoney \& McEvoy, 2012). Moreover, IU is also associated with various factors that underlie such internalizing symptoms, such as greater rumination (Liao \& Wei, 2011), elevated anxiety sensitivity (Carleton et al., 2007), and increased checking behavior (Tolin et al., 2003). As such, IU is considered a transdiagnostic risk and maintaining factor for internalizing disorders (McEvoy et al., 2019). Two subfactors of IU are thought to capture different ways people interpret and respond to uncertainty. Prospective IU (P-IU) reflects a desire for predictability and active seeking of certainty, while inhibitory IU (I-IU) points towards avoidance, behavioral inhibition, and paralysis in the face of uncertainty (Carleton, 2012).

\subsection{Relationships between ERN, IU and psychopathology}

Studies examining the relationship between IU and the ERN are limited and pose some contradictions. Two studies did not find a direct association between the total score of IU and the ERN (Jackson et al., 2016; Ruchensky et al., 2020). Concerning the IU subfactors, Jackson et al. (2016) observed that both subfactors had opposing associations with the ERN during a flanker task, which requires participants to rapidly discriminate a single centered element (e.g., letter) in a string (Eriksen \& Eriksen, 1974). ERN amplitude was enhanced for prospective IU but attenuated for inhibitory IU. The enhanced ERN in P-IU might have 
indicated an increase in performance monitoring in response to an error, however, this did not translate into better overall task accuracy for this group (with P-IU and I-IU performing comparably). Relatedly, Jackson et al. (2016) also found behavioral associations with IU subfactors; P-IU was associated with slower post-correct reaction time (RT) and higher I-IU with faster RT for post-corrects and post-errors. Post-error slowing (PES) is the behavioral adaptation characterized by increased RTs on trials that follow error commission compared to correct ones (Schroder et al., 2020), and an indication that processes responsible for cognitive control have responded to the ERN (Weinberg et al., 2016).

These findings of differential ERN amplitude for IU subfactors in Jackson et al. (2016) were not replicated by Sandre and Weinberg (2019) who found no association between the ERN and either subscale during a flanker task. However, Sandre and Weinberg (2019) employed a modified version of the flanker task that also included ambiguous trials (i.e., where they explicitly instructed participants there would be no right or wrong responses instructions were given). Inhibitory IU was associated with a smaller negative deflection in response to these trials. If this response to ambiguous trials still represents a response to the possibility of having made an error, Sandre and Weinberg's evidence of blunted performance monitoring for I-IU under conditions of uncertainty is not completely at odds with the I-IUERN attenuation found by Jackson and colleagues (2016). Still, the exact relationship between the IU subtypes and the ERN remains inconclusive. In the only study examining IU, ERN and psychopathology symptoms, Ruchensky et al. (2020) found that IU moderated the relationship between depression and the ERN. Specifically, depression symptoms were associated with a larger ERN, but only when IU was low (with no depression-ERN relationship at high levels of IU). Of note, Ruchensky et al. (2020) found no significant results when examining the subscales of IU. The authors contend that one reason previous research may have failed to find an association between depression and the ERN (e.g., Moran et al., 2017) was by not considering other underlying confounding variables, such as IU.

\subsection{The Present Study}

This study aimed to investigate various relationships between intolerance of uncertainty, self-reported symptoms of anxiety/depression, and brain activity associated with error processing. We sought to extend the small body of literature focused on ERN and IU, where evidence has thus far been inconclusive (Jackson et al., 2016; Ruchensky et al., 2020; Sandre \& Weinberg, 2019). Importantly, our replication used a large sample of undergraduates $(N=182)$ to ensure high statistical power in order to avoid the presence of chance findings which can occur with smaller samples. High-powered replications are 
especially needed considering the context of the replication crisis in ERP research (Clayson et al., 2019), whereby low samples can lead to an overestimation of the associations between electrophysiological and self-report variables ("false-positives"; Bernoster et al., 2019; Larson \& Carbine, 2017). Our well-powered sample aims to disentangle discrepancies in the literature surrounding our constructs of interest. Specifically, mixed findings regarding the effect of IU subfactors on ERN amplitudes (Jackson et al., 2016; Sandre \& Weinberg, 2019), mixed findings for direct relationships between depression error monitoring (Moran et al., 2017), and prior potential overestimation of the relationship between ERN and trait anxiety (Saunders \& Inzlicht, 2020). We have attempted an experimental replication of Jackson et al. (2016) and Ruchensky et al. (2020), which seeks to verify previous findings using certain variables while adjusting the experimental procedure (Hudson, 2021). By these adjustments it differs from a direct or exact replication, which aims to repeat the identical procedure of it's reference. An experimental replication, on the other hand, seeks increased generalization of findings that were obtained by a specific design. We employed a version of the flanker task that has been previously used with other populations (Andreu et al., 2017; Bernoster et al., 2019; Franken et al., 2007, 2010, 2018; Zijlmans et al., 2021). While it differs from our replication references (Jackson et al., 2016; Ruchensky et al., 2020) in several features (i.e., the duration of stimulus presentation, type of stimulus, out-of-time feedback inclusion, number of trials and blocks), this modified version does evoke the equivalent behavioral and neural effects related to performance monitoring (Franken et al., 2007, 2010).

The first objective of this study was to examine the relationship between the IU subfactors, ERN amplitudes and post-error slowing. Contradictions exist between Jackson et al. (2016) who found an enhanced ERN for P-IU compared to I-IU, and Sandre and Weinberg (2019), who found no effect. It should be noted that Sandre and Weinberg (2019) did find an attenuated ERN for ambiguous (feedback not given) trials, which we have argued could overlap with error trials. Therefore, we expected to replicate the results of Jackson et al. (2016) whereby P-IU would be associated with an enhanced ERN while I-IU would be associated with an attenuated ERN (Hypothesis 1). Both Ruchensky et al. (2020) and Jackson et al. (2016) found no relationship between ERN and total IU, as such, we expected the same (Hypothesis 2). Similar to Jackson et al. (2016) we expected to find an effect of IU subfactor on post-error and post-correct RTs: we expected slower RT in higher P-IU after correct trials and faster RT for increased I-IU in both correct and error trials. Additionally, we calculated post-error slowing (PES) as difference scores by subtracting average reaction time after correct responses from average reaction time after error responses (Schroder et al., 2020) 
which we expected would not be associated with IU scores (Ruchensky et al., 2020; Hypothesis 3). The second aim of this study was to perform a replication of the moderation analysis of Ruchensky et al. (2020). As such, we hypothesized that depression and IU would interact to predict the $\triangle E R N$ (i.e., difference in amplitudes between error trials and correct trials), such that higher levels of depression would be associated with larger $\Delta E R N s$ at low (but not medium or high) levels of IU.

\section{Materials and Methods}

The hypotheses and methods of this study were pre-registered. The preregistration, all data and analyses (including R scripts) are publicly available at https://osf.io/c5yr3.

\subsection{Participants}

In total, 212 psychology undergraduate students from Erasmus University Rotterdam were invited to the lab session via an online recruitment system. After the data-related (EEG, responses) exclusion criteria (see below) were applied, a final sample of 182 participants were used for all analyses (age range from 17 to 46 years $[M=21.2, S D=3.31]$; 82\% female; $54 \%$ Dutch). A breakdown of their ethnic self-identification was $75 \%$ for White/Caucasian, 9\% for Asian, 4\% for Middle Eastern, 3\% for Black, 2\% for mixed, 2\% for Latin-American, and around 5\% for Other and non-declared. Participants received course credit and monetary compensation (€5) related to a different task in the same session (see Procedure). A priori exclusion criteria were family history of photic epilepsy, related to another task that used flickering images, and psychopathology (self-report). Informed consent was obtained before participation, and the research protocol was approved by the ethical board of the Erasmus School of Behavioural and Social Sciences.

\subsection{Questionnaires}

After finishing the experimental protocol, participants completed the following selfreport questionnaires (either in Dutch or English, for Dutch or international students, respectively):

The Intolerance of Uncertainty, Short Form (IUS-12; Carleton et al., 2007) is a shortened version of the original 27-item Intolerance of Uncertainty Scale (Freeston et al., 1994; Dutch translation: de Bruin et al., 2006). It assesses the degree to which individuals find uncertain scenarios distressing and undesirable, as well as their reactions to them. The items are rated on a five-point Likert scale ranging from 1 (not at all characteristic of me) to 5 (entirely characteristic of me). The scale ranges from 12 to 60, with higher scores indicating higher intolerance of uncertainty. In addition to the total score, two subfactors can be extracted, Prospective IU (7 items) and Inhibitory IU (5 items; McEvoy \& Mahoney, 2011). 
Internal consistency was acceptable - good for the total scale IU $(\alpha=0.86)$ and both subfactors P-IU $(\alpha=0.81)$ and I-IU $(\alpha=0.76)$.

The Beck Depression Inventory, Second Edition (BDI-II; Beck et al., 1996; Dutch translation: Does, 2002) is a widely used self-report measure of depressive symptoms, both cognitive and somatic. It consists of 21 items where participants rate items on a four-point Likert scale ranging from 0 to 3 based on perceived severity in the last two weeks. The score ranges from 0 to 63 , with higher scores indicating more severe depression symptoms. Internal consistency of this scale was good $(\alpha=0.94)$.

The Penn State Worry Questionnaire (PSWQ; Meyer et al., 1990; Dutch translation: Van Rijsoort et al., 1999) is a 16-item self-report questionnaire that measures the trait of worry across the dimensions of excessiveness, generality and uncontrollability. Each item is rated on a five-point Likert scale from 1 (not at all typical of me) to 5 (very typical of me). The scale ranges from 16 to 80 with higher scores indicative of higher levels of trait worry. Internal consistency of this scale was good $(\alpha=0.83)$.

The trait subscale of the State Trait Anxiety Inventory, Form Y (STAI-T; Spielberger, 1983; Dutch translation: Ploeg, 2000) is a self-report questionnaire consisting of 20 items that measure someone's general propensity for anxiety. Respondents rate items based on how they generally feel, using a four-point Likert scale from 1 (almost never) to 4 (almost always), with higher scores indicating greater anxiety (range: 20 to 80). Internal consistency of this scale was acceptable $(\alpha=0.76)$.

\subsection{Task and materials}

Participants completed an adapted version of the Eriksen flanker task (Franken et al., 2010). The task was programmed in E-prime 3 software (Psychology Software Tools, Pittsburgh, PA). There were four types of a letter string: two congruent (HHHHH and SSSSS) and two incongruent (SSHSS and HHSHH). The target letters array was displayed in white against a black background on a 20 -inch PC monitor with a resolution of $1024 \times 768$ pixels which was placed at a distance of $120 \mathrm{~cm}$ from the seated participant. Participants were instructed to answer by pressing either ' 1 ' or ' 5 ' on a QWERTY keyboard, as fast and accurately as possible, if the middle letter was either $\mathrm{H}$ or $\mathrm{S}$. Those number buttons were associated with $\mathrm{H}$ and $\mathrm{S}$ in the instructions and the association was counterbalanced among participants.

A schematic depicting the progression of each trial can be seen in Figure 1. Each trial started with a fixation cross (+) visible for $150 \mathrm{~ms}$, followed by a blank screen of random duration between 100 to $150 \mathrm{~ms}$. The letters were displayed for $50 \mathrm{~ms}$. Participants had 700 
$\mathrm{ms}$ to respond using both hands. After each trial, participants received feedback for $500 \mathrm{~ms}$ in red font (OOO for correct; XXX for incorrect; ! for no answer). The inter-trial interval (ITI) had a duration of $500 \mathrm{~ms}$. Participants completed a practice block of eight trials and the actual task consisted of five blocks of 80 trials with self-administered breaks in between (400 total trials). Participant response type (correct or incorrect) and reaction time (in ms) on every trial was recorded for later analysis.

\section{Figure 1}

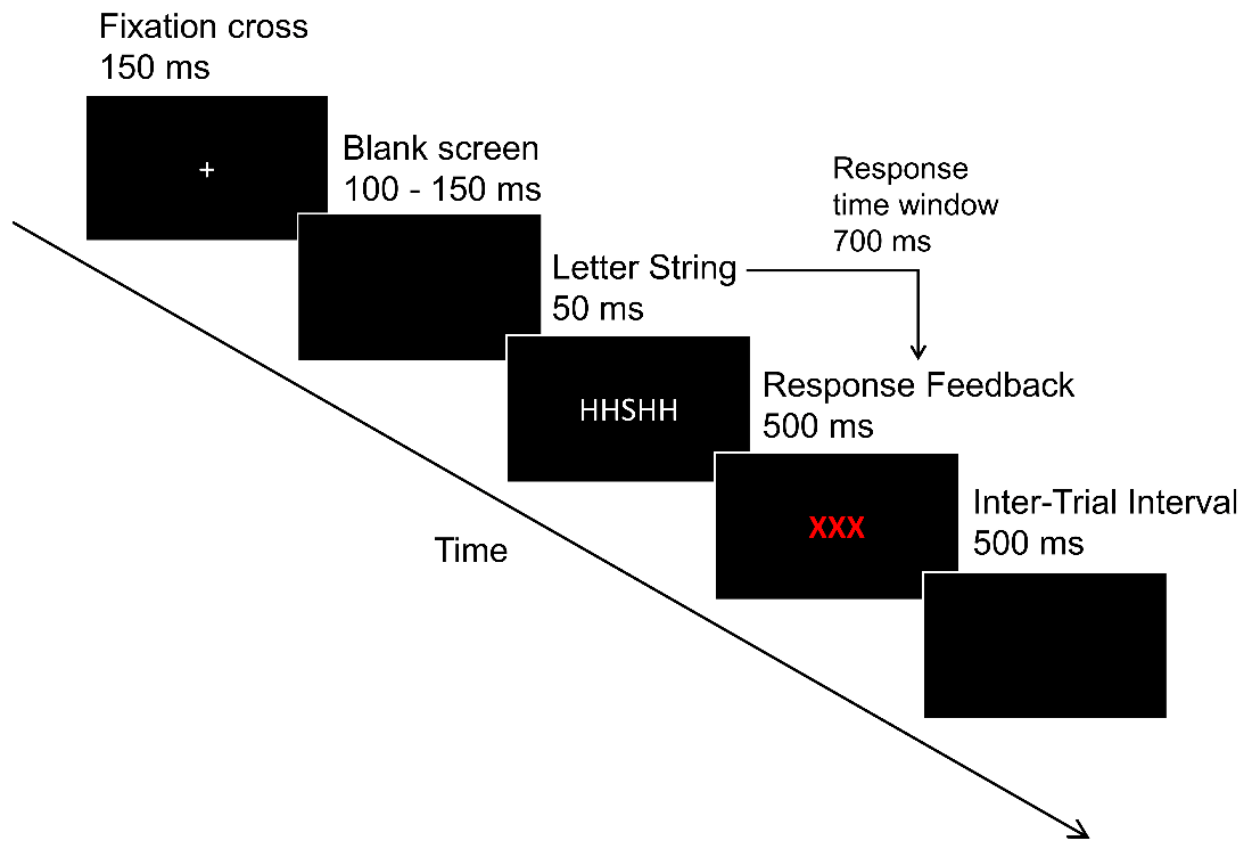

Figure 1. Schematic of a flanker task trial. A single trial lasted between 1600 and $1650 \mathrm{~ms}$ (accounting for the variable duration of the blank screen). A fixation cross was presented for $150 \mathrm{~ms}$, followed by a blank screen for $100-150 \mathrm{~ms}$. The letter string was presented for 50 $\mathrm{ms}$, then the screen remained blank for a further $650 \mathrm{~ms}$ (giving participants a $700 \mathrm{~ms}$ time frame to indicate their response). Feedback was then shown for $150 \mathrm{~ms}$ (XXX for incorrect, OOO for correct, ! for "too late") and the trial ended with a blank screen of $500 \mathrm{~ms}$.

\subsection{Procedure}

After arrival at the lab, participants received a verbal description of the experimental procedure from the researcher in charge and provided written informed consent. After this, they were sat in an isolated dimly-lit room where the EEG was attached. The estimated duration of the whole experimental procedure was as follows: first, they performed a Doors task (40 min) followed by a long break (10 min), secondly, there was a Fear Conditioning task (25 min), both tasks not reported here. After a last break (10 min), they performed the Flanker task (15 min). Duration lengths are estimated and vary according to self-administered 
breaks during the tasks. During the long breaks the researcher checked the overall status of the participant.

\subsection{EEG recording and processing}

Continuous EEG was recorded using a 32+2 electrodes cap arranged according to the 10/20 layout. Electro-oculogram (EOG) was recorded using 4 external electrodes: two above and below the left eye, and another two at the outer canthus of each eye. All electrodes were sintered $\mathrm{Ag} / \mathrm{AgCl}$ electrodes. Data were recorded using the Active-Two BioSemi system (BioSemi, Amsterdam, Netherlands). This system includes two additional electrodes, CMS (Common Mode Sense) and DRL (Driven Right Leg), that serve as online reference and ground. The EEG data were digitized at a $512 \mathrm{~Hz}$ sampling rate and 24-bit A/D conversion. All electrode impedances were kept below $20 \mathrm{k} \Omega$.

Offline EEG data were analyzed with Brain Vision Analyzer 2 (Brain Products, Gilching, Germany). Data were re-referenced to the average voltage at all scalp electrodes (i.e., average reference), band-pass filtered from 0.1 to $35 \mathrm{~Hz}$ (Butterworth zero phase filter with a $24 \mathrm{~dB}$ /octave roll-off), notch-filtered at $50 \mathrm{~Hz}$, and corrected for eye movement artifacts (Gratton et al., 1983). Data were segmented in epochs of $1200 \mathrm{~ms}$ (400 ms before and $800 \mathrm{~ms}$ after response). Artifact rejection was applied to all epochs using: (a) an amplitude criterion of $\pm 75 \mu \mathrm{V}$, (b) a gradient criterion of $\pm 50 \mu \mathrm{V} / \mathrm{ms}$, (c) a difference criterion of $200 \mu \mathrm{V}$ and (d) a low activity criterion of $2 \mu \mathrm{V}$ (interval length: $200 \mathrm{~ms}$ ). Baseline correction was applied using the interval from 400 to $200 \mathrm{~ms}$ pre-response (Weinberg et al., 2010). Exclusion criteria based on the behavioral performance were: (a) participants who missed $>20 \%$ of trials of the flanker task $(n=3)$, or $(b)$ participants who scored $<55 \%$ accuracy $(\mathrm{n}=10$; Seow et al., 2020). In addition, (c) participants with less than 10 commission errors are also excluded $(n=6$; Olvet \& Hajcak, 2009). Finally, (d) trials with reaction times below $200 \mathrm{~ms}$ were not further considered in the analysis (Sandre et al., 2020; Weinberg, Kotov, et al., 2015). Altogether, 182 full datasets remained for further analysis after applying these criteria. The average number of error and correct trials in our sample was $44.09(S D=25.49)$, and $290.64(S D=64.01)$, respectively.

\subsection{Power calculations}

Power calculations for linear multiple regression were performed using G*Power3 (Faul et al., 2007). For analyses predicting the ERN amplitude from IU subfactors, we entered a minimum effect size of $f^{2}=0.11$ (corresponding to the $R^{2}$ of 0.10 found by Jackson and colleagues [2016]), an alpha level of 0.05 and two predictors. A-priori tests showed that a sample size of $N=90$ was required to achieve a power of 0.80 . For our moderation analysis, 
we entered a minimum effect size of $f^{2}=0.09$ (corresponding to the $R^{2}$ of 0.08 found by Ruchensky and colleagues [2020]), an alpha level of 0.05 and two predictors. A-priori tests showed that a sample size of $N=114$ was required to achieve a power of 0.80 . After applying the exclusion criteria, the sample size of this study $(N=182)$ had a power of 0.95 to detect an effect size of $f^{2}=0.09$, and a power of 0.98 to detect an effect size of $f^{2}=0.11$.

\subsection{Data analysis}

Average ERP waves were calculated for artifact-free trials at each electrode of interest in two conditions (correct and incorrect responses). The ERN and CRN were defined as the mean activity on error and correct trials, respectively, at 0 to $100 \mathrm{~ms}$ after the participant's response at $\mathrm{Cz}$ electrode, where the signal was maximal (Sandre et al., 2020), see Figure 2a. The Pe and Pc were defined as the mean activity on error and correct trials, respectively, at 200 to $400 \mathrm{~ms}$ after response at both $\mathrm{Cz}$ and Pz electrodes (Ruchensky et al., 2020), see Figure $2 \mathrm{~b}$. We also calculated difference potentials to account for individual variation between correct and error trials. This is referred to as $\triangle \mathrm{ERN}$ and $\triangle \mathrm{Pe}$, calculated as the difference between the respective error potential amplitude and correct potential amplitude (e.g., ERN - CRN).

The behavioral measures extracted from the flanker task were: (1) number of correct trials (accuracy); (2) RT of the correct and incorrect trials; (3) average RTs of the next trial after error and correct feedback (i.e., post-correct and post-error RTs); (4) post-error slowing (PES), as the difference between average RT after error trials and the average RT after correct trials. 
Figure 2

A

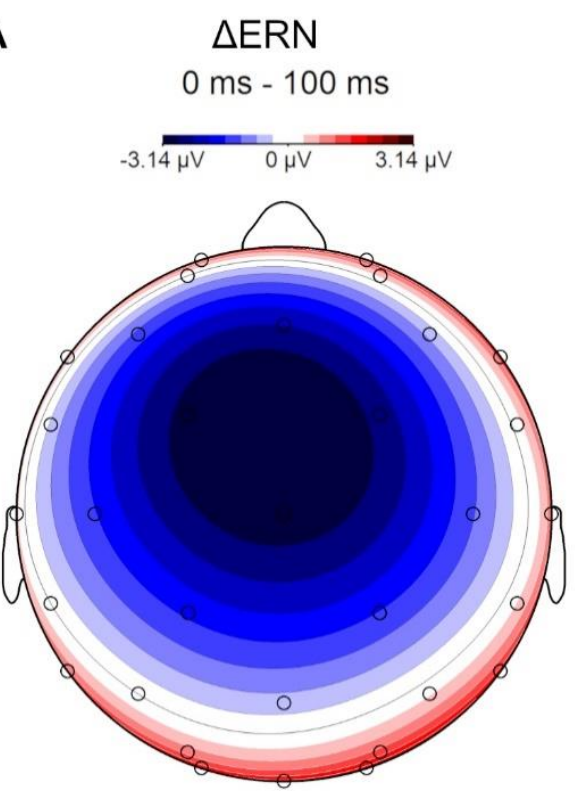

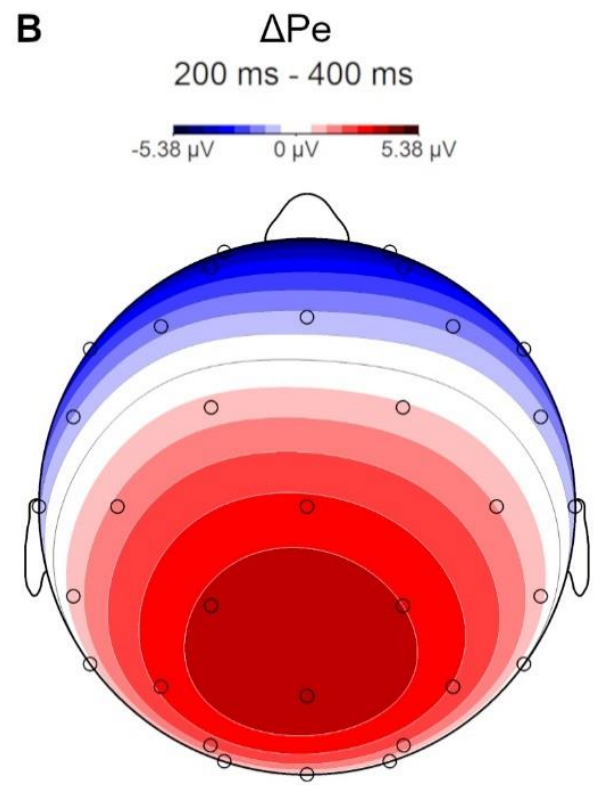

Figure 2. Topographic map depicting the average difference $(\mu \mathrm{V})$ between error and correct responses. Scalp maps display the grand average voltage distribution of (A) $\triangle E R N$ from 0 $100 \mathrm{~ms}$ post-response, and (B) $\Delta \mathrm{Pe}$ from $200-400 \mathrm{~ms}$ post-response. The voltage distributions are plotted on a minimum-maximum scale going from blue (negative polarity) to red (positive polarity). Compared to other electrodes, the most pronounced negative polarities were seen at $\mathrm{Cz}$ for the $\Delta \mathrm{ERN}$ and $\mathrm{Pz} / \mathrm{Cz}$ for the $\Delta \mathrm{Pe}$, during their respective time windows.

To examine the effects of the IU subfactors on performance monitoring, we ran a multiple regression using both IU subfactors (P-IU and I-IU) as simultaneous predictors and the ERN as the dependent variable. Next, we ran a simple linear regression with total IU as predictor as the ERN as the dependent variable. Further exploratory regression analyses were run for several dependent variables (ERN, Pe and RTs) using both total IU (single predictor) and the IU subfactors (simultaneous predictors). To assess the effect that depression and trait anxiety has on the relationship between IU and performance monitoring, we conducted a moderation analysis. Depression and trait anxiety levels were based on the participants' scores in the BDI-II and the trait scale of the STAI, respectively. For this, we conducted a multiple regression with total IU and the interaction term (depression $\times$ total IU) entered simultaneously to predict the $\triangle E R N$, based on Ruchensky et al. (2020). Predictors were mean centered. Similar exploratory analyses were performed substituting (a) trait anxiety scores in the interaction term and (b) using $\Delta \mathrm{Pe}$ as the outcome variable.

All analyses were performed using R Statistical Software (v4.1.2; R Core Team, 2021). The assumptions for multiple linear regression were tested prior to running each confirmatory analysis and can be viewed in the Supplemental Material. Our outlier treatment 
was consistent with the replication references: for the regression analyses we removed univariate outliers from the ERN data (Jackson et al., 2016), while for the moderation analysis neither univariate or multivariate outliers were removed (Ruchensky et al., 2020). Correlations, t-tests, and regressions were performed using the 'stats' package (R Core Team, 2021). The figures were generated using the 'jtools' (Long, 2020) and 'ggplot2' (Wickham, 2016) packages, and a tutorial by Craddock (2016).

\section{Results}

Table 1 shows means, standard deviations, and correlations for variables of interest. Correlations ranged from small (STAI-T and Pc, $r=-.15, p<.05$ ) to large (P-IU and I-IU, $r$ $=.61, p<.01)$, with the IU subfactors having very large correlations with their parent measure (P-IU and IUS-12, $r=.93, p<.01$; I-IU and IUS-12, $r=.86, p<.01$ ). Moreover, both measures of the ERN were uncorrelated with any questionnaire variables. In contrast, the CRN amplitude correlated with total IU and both subfactors, as well as with STAI-T (all $p$ values <.01). Regarding the behavioral measures (i.e. Correct \% and PES), both correlated with either Pe calculation approach $(\Delta \mathrm{Pe}$ and $\mathrm{Pe})$, and the accuracy rate was also related to the amplitudes of $\triangle \mathrm{ERN}$ and CRN. Further, both behavioral measures correlated negatively with trait anxiety scores, while PES was in addition negatively associated with I-IU scores. Interestingly, accuracy and PES were correlated with each other such that a higher accuracy rate was associated with longer PES $(r=.35, p=<.01)$. 


\section{Table 1}

Means, Standard Deviations, and Correlations of Study Variables

\begin{tabular}{|c|c|c|c|c|c|c|c|c|c|c|c|c|c|c|c|c|}
\hline Column Label & $M$ & $S D$ & 1 & 2 & 3 & 4 & 5 & 6 & 7 & 8 & 9 & 10 & 11 & 12 & 13 & 14 \\
\hline 1. $\Delta \mathrm{ERN}(\mu \mathrm{V})$ & -3.17 & 3.12 & 1 & . & . & . & . & . & . & . & . & . & . & . & . & . \\
\hline 2. $\Delta \mathrm{Pe}(\mu \mathrm{V})$ & 3.44 & 2.39 & $.30 * *$ & 1 & . & . & . & . & . & . & . & . & . & . & . & . \\
\hline 3. $\mathrm{ERN}(\mu \mathrm{V})$ & 0.32 & 3.57 & $.73 * *$ & $.43 * *$ & 1 & . & . & . & . & . & . & . & . & . & . & . \\
\hline 4. CRN $(\mu \mathrm{V})$ & 3.49 & 2.48 & $-.20 * *$ & $.23 * *$ & $.52 * *$ & 1 & . & . & . & . & . & . & . & . & . & . \\
\hline 5. $\mathrm{Pe}(\mu \mathrm{V})$ & 4.12 & 2.5 & .04 & $.75^{* *}$ & $.39 * *$ & $.51 * *$ & 1 & . & . & . & . & . & . & . & . & . \\
\hline 6. $\mathrm{Pc}(\mu \mathrm{V})$ & 0.68 & 1.74 & $-.36 * *$ & $-.30 * *$ & -.02 & $.42 * *$ & $.41 * *$ & 1 & . & . & . & . & . & . & . & . \\
\hline 7. IUS-12 & 29.38 & 7.93 & .07 & -.09 & -.12 & $-.25^{* *}$ & -.12 & -.06 & 1 & . & . & . & 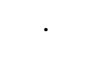 & . & . & . \\
\hline 8. P-IU & 18.23 & 5.14 & .02 & -.12 & -.14 & $-.23 * *$ & -.12 & .00 & $.93 * *$ & 1 & . & . & . & . & . & . \\
\hline 9. I-IU & 11.15 & 3.65 & .12 & -.02 & -.05 & $-.23 * *$ & -.10 & -.12 & $.86^{* * *}$ & $.61^{* *}$ & 1 & . & . & . & . & . \\
\hline 10. STAI-T & 45.35 & 7.91 & .06 & -.11 & -.09 & $-.20 * *$ & $-.21 * *$ & $-.15^{*}$ & $.37 * *$ & $.27 * *$ & $.42 * *$ & 1 & & . & . & . \\
\hline 11. BDI-II & 5.76 & 7.71 & .05 & -.06 & -.05 & -.13 & -.12 & -.09 & $.27 * *$ & $.18^{*}$ & $.34 * *$ & $.40 * *$ & 1 & . & . & . \\
\hline 12. PSWQ & 45.11 & 10.81 & -.05 & -.06 & -.14 & -.14 & -.14 & -.13 & $.48 * *$ & $.38 * *$ & $.50 * *$ & $.54 * *$ & $.62 * *$ & 1 & . & . \\
\hline 13. Correct $\%$ & 82.19 & 9.34 & $-.18^{*}$ & $.33^{* *}$ & -.04 & $.17^{*}$ & $.31 * *$ & -.01 & -.11 & -.08 & -.13 & $-.29 * *$ & -.07 & -.08 & 1 & . \\
\hline 14. PES (ms) & 20.38 & 30.28 & .03 & $.15^{*}$ & -.01 & -.05 & $.19^{*}$ & .07 & -.10 & -.05 & $-.15^{*}$ & $-.18 *$ & -.07 & -.09 & $.35^{* *}$ & 1 \\
\hline 15. Age & 21.21 & 3.32 & $-.19 * *$ & $-.19 *$ & -.07 & .14 & -.08 & .14 & -.14 & -.09 & $-.18^{*}$ & -.10 & $-.19 *$ & -.14 & $.18^{*}$ & -.04 \\
\hline
\end{tabular}

Note. $N=182$. ERN = Error related negativity; Pe = Error positivity; CRN = Correct response negativity; Pc = Correct positivity; IUS-12 = Intolerance of Uncertainty, Short Form; P-IU = Prospective IU; I-IU = Inhibitory IU; STAI-T = Trait subscale of the State-Trait Anxiety Inventory; BDI-II = Beck

Depression Inventory, Second Edition; PSWQ = Penn State Worry Questionnaire; Correct $\%=$ percentage of correct responses; PES = PES traditional [Mean Post- Error RT - Mean Post- Correct RT]. Pearson product-moment correlation coefficients are given.

*indicates $p<.05$. ** indicates $p<.01$ 


\subsection{Behavioural Results}

Table 2 displays selected behavioural data for the flanker task. Paired-sample t-tests revealed behavioural patterns typical for the task. Mean error counts were larger for incongruent trials $(M=35.02, S D=15.73)$, relative to congruent trials $\left(M=14.64, S D=10.94 ; t_{181}=-26.58\right.$, $95 \%$ confidence interval $(\mathrm{CI})[-21.89,-18.87], p<.001, d=1.97)$. Participants were faster on congruent trials $(M=446.00 \mathrm{~ms}, S D=26.88 \mathrm{~ms})$ versus incongruent trials $(M=478.85 \mathrm{~ms}$, $S D=29.64 \mathrm{~ms} ; t_{181}=-30.92,95 \%$ CI $\left.[-34.95,-30.76], p<.001, d=2.29\right)$. Participants were also faster on error $(M=418.90 \mathrm{~ms}, S D=38.78 \mathrm{~ms})$ compared to correct trials $(M=469.08$ $\mathrm{ms}, S D=26.15 \mathrm{~ms} ; t_{181}=-25.19,95 \%$ CI [-54.10, -46.24], $\left.p<.001, d=1.87\right)$. Finally, posterror mean RTs $(M=480.45 \mathrm{~ms}, S D=40.38 \mathrm{~ms})$ were slower than post-correct mean RTs $(M$ $=460.07 \mathrm{~ms}, S D=27.48 \mathrm{~ms} ; t_{181}=-9.08,95 \%$ CI $\left.[-24.81,-15.95], p<.001, d=0.67\right)$.

\section{Table 2}

Descriptive Statistics of Flanker Task Behavioural Data

\begin{tabular}{ccccc}
\hline & $M$ & $S D$ & Minimum & Maximum \\
\hline Accuracy $(n)$ & & & & \\
Correct & 328.75 & 37.37 & 229 & 382 \\
Error & 49.66 & 25.04 & 12 & 128 \\
Missed & 19.13 & 14.90 & 2 & 79 \\
Average RT (ms) & 462.25 & 27.27 & 387.19 & 531.92 \\
Correct & 469.08 & 26.15 & 396.26 & 541.89 \\
Error & 418.90 & 38.78 & 304.70 & 517.18 \\
Post-correct & 460.07 & 27.48 & 389.89 & 538.46 \\
Post-error & 480.45 & 40.38 & 335.81 & 599.08 \\
\hline
\end{tabular}

Note. $\mathrm{N}=182$. Participants completed 400 trials. The average accuracy rate was $82.19 \%$, the average inaccuracy rate was $12.41 \%$ and the average rate of missed responses was $4.78 \%$.

\subsection{ERPs}

Grand average ERP waveforms at electrode $\mathrm{Cz}$ are presented in Figure 3a for the ERN and CRN. Across the sample, the ERN exhibited a mean amplitude of $0.32 \mu \mathrm{v}(S D=3.57 \mu \mathrm{v})$ while the $C R N$ had a mean amplitude of $3.49 \mu \mathrm{v}(S D=2.48 \mu \mathrm{v})$. A paired sample t-test revealed that the ERN was larger (i.e., more negative) than the CRN within the 0-100 ms window $\left(t_{181}=13.72,95 \%\right.$ CI $\left.[2.71,3.63], p<.001, d=1.02\right)$. 
Grand average ERP waveforms at electrode $\mathrm{Cz}$ are presented in Figure $3 \mathrm{~b}$ for the $\mathrm{Pe}$ and Pc. Across the sample, the Pe exhibited a mean amplitude of $4.12 \mu \mathrm{v}(S D=2.50 \mu \mathrm{v})$ while the Pc had a mean amplitude of $0.68 \mu \mathrm{v}(S D=1.74 \mu \mathrm{v})$. A paired sample t-test revealed that the Pc was larger (i.e., more negative) than the Pe within the $200-400 \mathrm{~ms}$ window $\left(t_{181}=-\right.$ $19.42,95 \%$ CI $[-3.79,-3.09], p<.001, d=1.44)$.

\section{Figure 3}
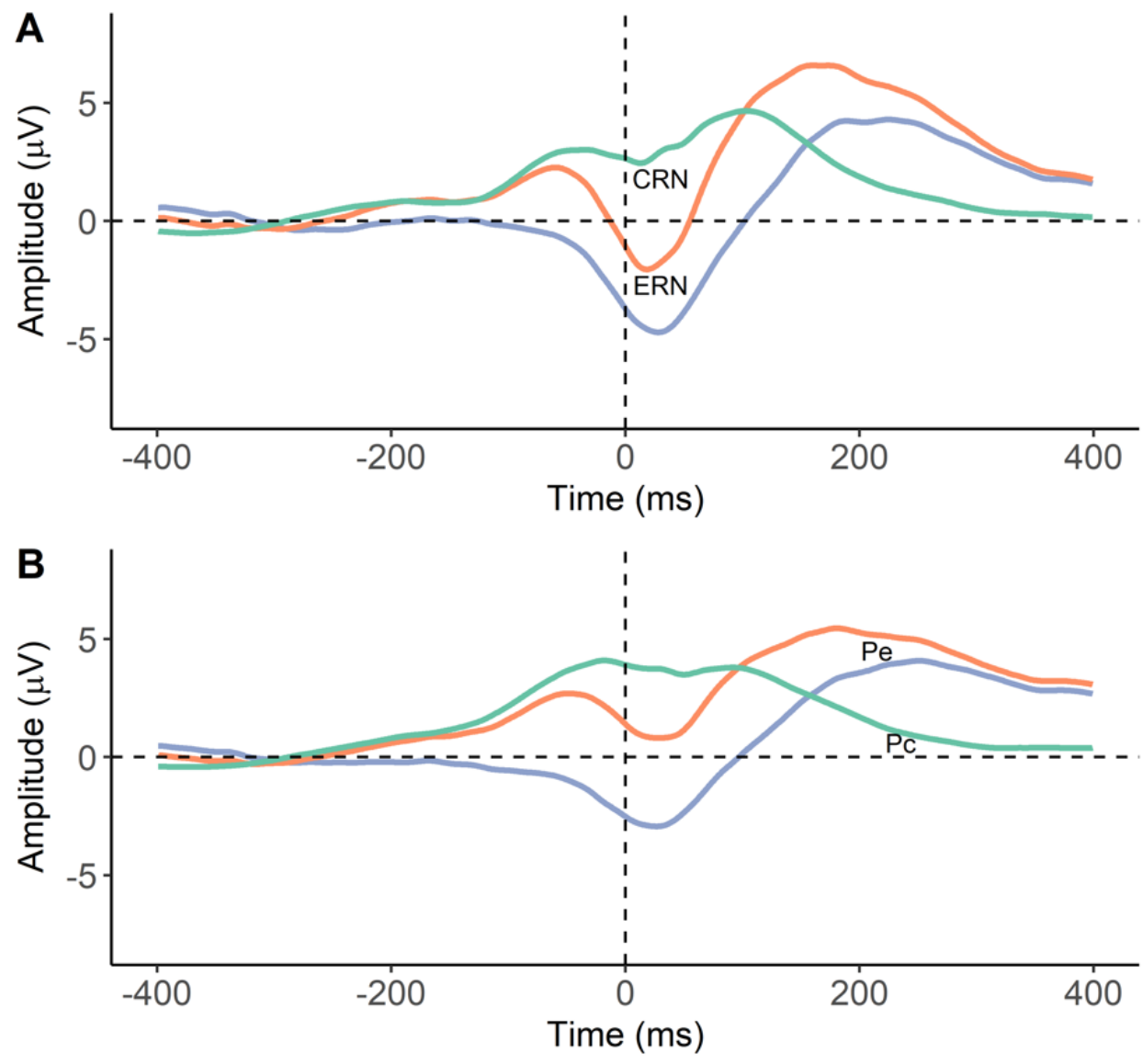

- Difference - Error trials - Correct trials

Figure 3. Response-locked grand average waveforms showing the ERN and Pe. Figure 3A shows grand average activity for error and correct trials at $\mathrm{Cz}$. Figure $3 \mathrm{~B}$ shows grand average activity for error and correct trials averaged across $\mathrm{Cz}$ and Pz. $0 \mathrm{~ms}$ represents response commission. Event-related potentials are labelled, indicating the peak of each wave between 0-100 ms post-onset (Figure 3A) and 200-400 ms post-onset (Figure 3B). ERN = error-related negativity; $\mathrm{CRN}=$ correct-related negativity; $\mathrm{Pe}=$ error-related positivity; $\mathrm{Pc}=$ correct-related positivity; Difference $=$ grand average amplitude of error trials minus average amplitude correct trials.

\subsection{Regression Analyses}

In line with Jackson et al. (2016), the ERN data was screened for univariate outliers using $\pm 1.5 \times$ interquartile range, leading to the removal of eight cases $(n=174)$. A linear 
regression was performed to predict ERN amplitude via total IU. The results of the regression indicated that total IU was unable to explain any variance in the ERN, $\left(F_{1,172}=3.28, p=\right.$ $\left..072, R^{2}=0.02\right)$, nor could total IU predict ERN amplitude $(\beta=-0.05, S E=0.03, t=-1.81, p$ $=.072$ ). A linear regression was then performed to predict ERN amplitude using P-IU and IIU as simultaneous predictors. The two predictors were unable to explain any variance in the $\mathrm{ERN}, F_{2,171}=2.11, p=.125, R^{2}=0.02$. Both P-IU $(\beta=-0.09, S E=0.05, t=-1.74, p=.083)$ and I-IU $(\beta=0.02, S E=0.08, t=0.25, p=.801)$ were unable to predict ERN amplitude.

A linear regression was performed to predict post-error RT using P-IU and I-IU as simultaneous predictors. The results of the regression indicated that two predictors were unable to explain any variance in post-error RT, $F_{2,171}=0.06, p=.942, R^{2}<0.01$. Both P-IU $(\beta=-0.20, S E=0.77, t=-0.26 p=.798)$ and I-IU $(\beta=-0.02, S E=1.08, t=-0.02, p=.985)$ were unable to predict post-error RT. Using PES index (i.e., mean RT after error minus mean RT after correct) as the dependent variable in the same regression model, the subfactors could not predict any variance in post-error slowing, $F_{2,171}=1.81, p=.166, R^{2}=0.02$. Both P-IU $(\beta=0.33, S E=0.58, t=0.58 p=.565)$ and I-IU $(\beta=-1.44, S E=0.81 t=-1.78, p=.078)$ were unable to predict post-error slowing.

\subsection{Moderation Analyses}

Table 3 presents results for regression analyses predicting the $\triangle \mathrm{ERN}$. There were no significant results when entering depression and IU into separate regressions to predict the $\triangle E R N$. Likewise, there were also no significant results when depression and IU were entered simultaneously to predict the $\triangle E R N$. Finally, a model including depression, IU and the interaction term (depression $\times \mathrm{IU})$ did not explain any variance in the $\Delta \mathrm{ERN}\left(F_{2,179}=0.52, p\right.$ $\left.=.599, R^{2}=<0.01\right)$; the predictors and their interaction were also not statistically significant (see Table 3 and Figure 4).

There were no significant results when entering trait anxiety and IU into separate regressions to predict the $\triangle \mathrm{ERN}$ (see Table 3). Likewise, there were also no significant results when trait anxiety and IU were entered simultaneously to predict the $\Delta E R N$. Finally, a model including trait anxiety, IU and the interaction term (trait anxiety $\times$ IU) did not explain any variance in the $\Delta \mathrm{ERN}\left(F_{3,179}=0.62, p=.601, R^{2}=.01\right)$; the predictors and their interaction were also not statistically significant (see Table 3 and Figure 5). 


\section{Table 3}

Standardized beta coefficients ( $\beta$ ) for regression analyses predicting the $\triangle E R N$

\begin{tabular}{lccc}
\hline & Model 1 & Model 2 & Model 3 \\
\hline Predictors (Depression) & 0.03 & 0.01 & 0.02 \\
Depression & 0.03 & 0.02 & 0.03 \\
Total IU & - & - & $<-0.01$ \\
Depression $\times$ IU & & & 0.01 \\
Predictors (Trait Anxiety) & 0.02 & 0.01 & 0.02 \\
Trait Anxiety & 0.03 & 0.02 & $<-0.01$ \\
Total IU & - & - & \\
Trait Anxiety $\times$ IU & & &
\end{tabular}

Note. Model $1=$ separate predictors; model $2=$ simultaneous predictors; model $3=$ simultaneous predictors plus interaction term. No coefficients were significant at $\mathrm{p}<.05$. These null results still held when using the absolute ERN amplitude as an outcome variable (see Supplement). 


\section{Figure 4}

1

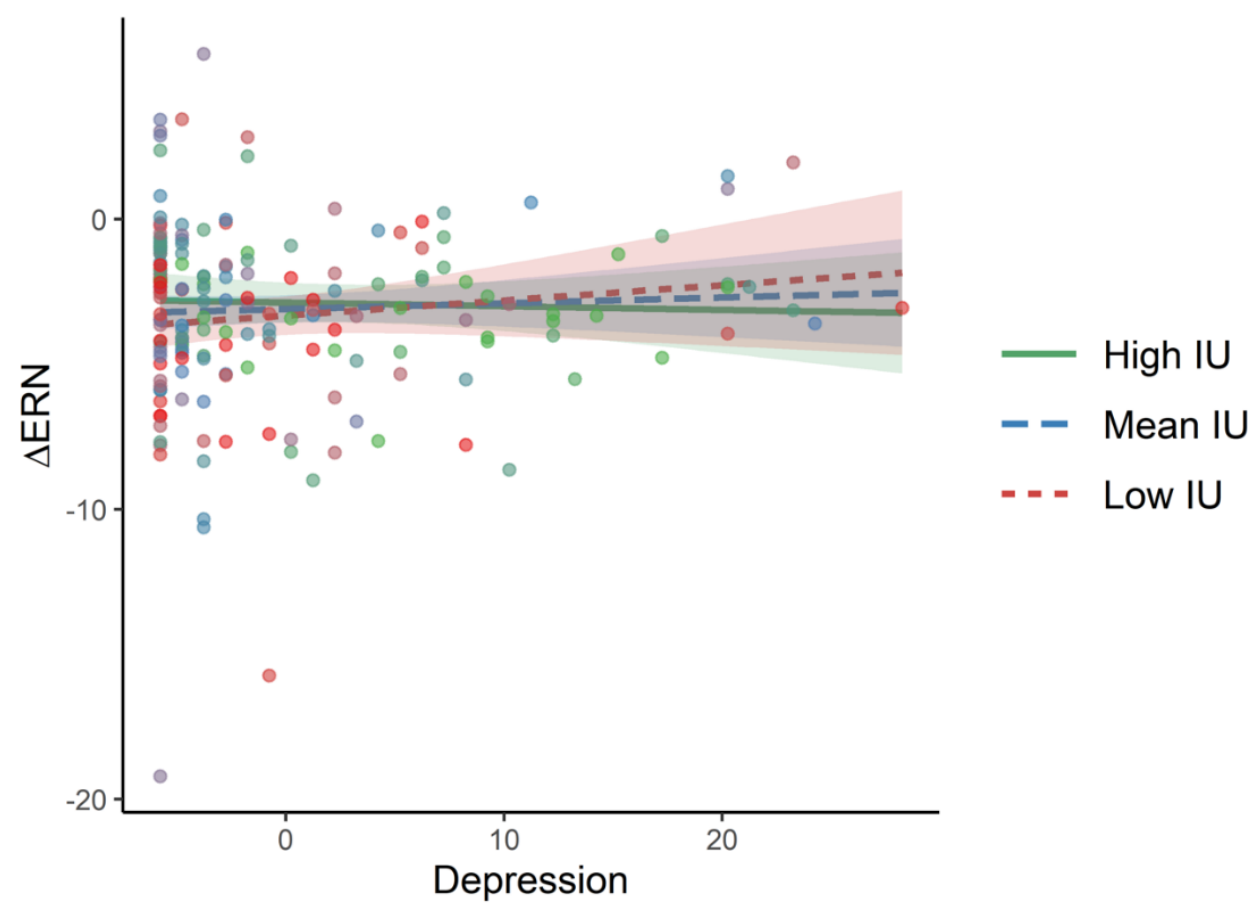

Figure 4. Relationship between depression and the $\triangle E R N$ at different levels of IU. The relationship between depression and $\triangle \mathrm{ERN}$ at low (red line; -1 SD), medium (blue line; mean) and high (green line; +1 SD) levels of IU. There were no main effects nor an interaction between any variables in predicting the outcome. 
Figure 5

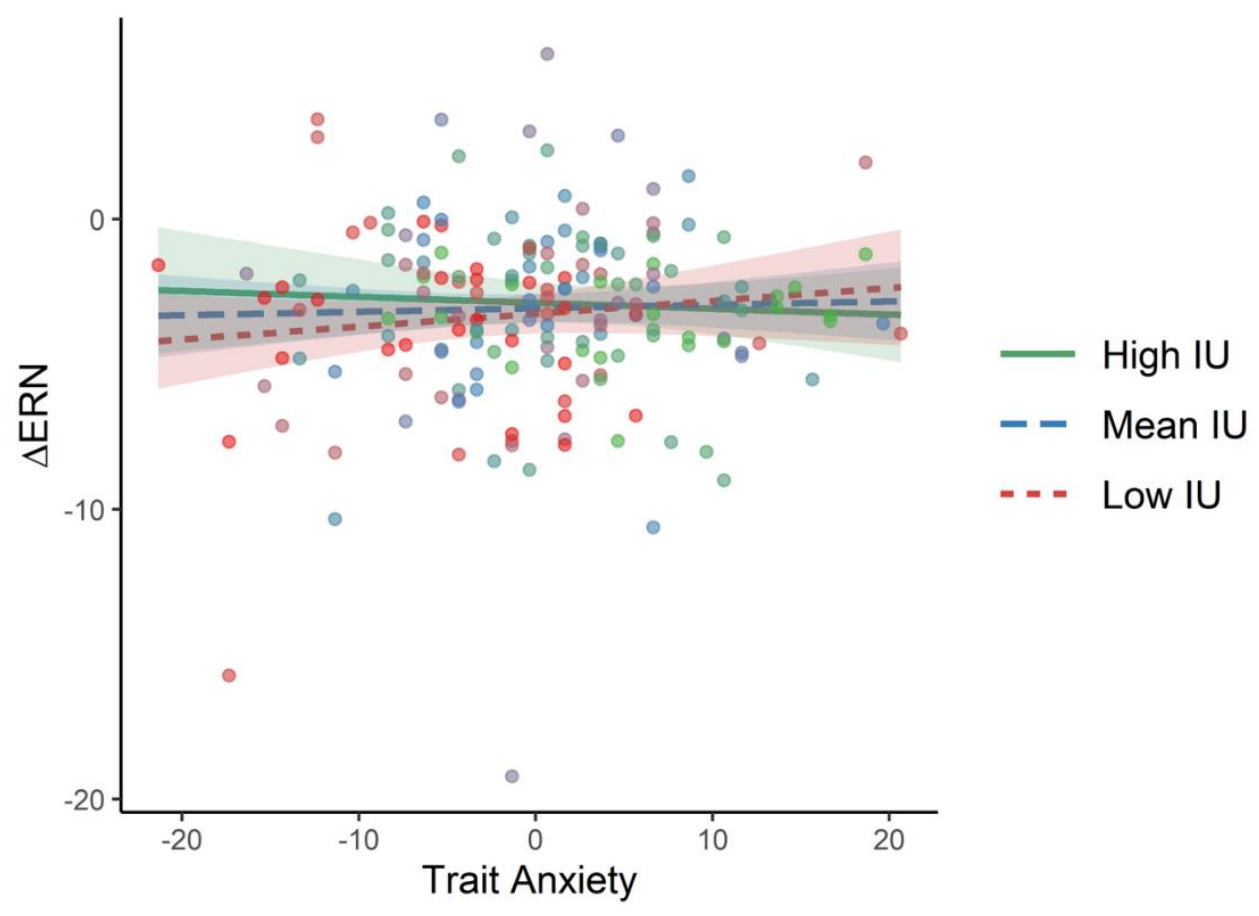

Figure 5. Relationship between trait anxiety and the $\triangle E R N$ at different levels of IU. The relationship between trait anxiety and $\triangle E R N$ at low (red line; $-1 \mathrm{SD}$ ), medium (blue line; mean) and high (green line; $+1 \mathrm{SD}$ ) levels of IU. There were no main effects nor an interaction between any variables in predicting the outcome.

\subsection{Exploratory regression analyses}

Several more simple and multiple regressions were run using total IU and the IU subfactors as predictors (see Table 4). Total IU explained $6 \%$ of the variance in correctresponse negativity, $F_{1,174}=10.18, p=.002, \mathrm{R}^{2}=0.06$. Neither total IU or the IU subfactors could predict any variance in the $\Delta \mathrm{ERN}, \mathrm{Pe}, \mathrm{Pc}$ or $\Delta \mathrm{Pe}$. 


\section{Table 4}

Standardized beta coefficients ( $\beta$ ) for exploratory regression analyses

\begin{tabular}{cccccc}
\hline Predictors & \multicolumn{3}{c}{ Outcome } \\
& $\mathrm{CRN}$ & $\Delta \mathrm{ERN}$ & $\mathrm{Pe}$ & $\mathrm{Pc}$ & $\Delta \mathrm{Pe}$ \\
\hline Total IU & $-0.07 * *$ & 0.03 & -0.04 & -0.01 & -0.03 \\
Simultaneous predictors & & & & & \\
P-IU & -0.07 & -0.02 & -0.04 & 0.02 & -0.06 \\
I-IU & -0.07 & 0.10 & -0.05 & -0.06 & 0.01 \\
\hline
\end{tabular}

Note. P-IU = Prospective intolerance of uncertainty; I-IU = Inhibitory intolerance of uncertainty.

$*$ indicates $p<.05 * *$ indicates $p<.01$

\section{Discussion}

Previous research has been inconclusive regarding the relationships between neural indices of performance monitoring, intolerance of uncertainty (including IU subfactors) and self-reported symptoms of anxiety and depression in non-clinical samples (Jackson et al., 2016; Ruchensky et al., 2020; Sandre \& Weinberg, 2019; Saunders \& Inzlicht, 2020). As such, we used a large sample with high statistical power to further clarify these relationships. As expected, total IU was not associated with the error-related negativity in our sample. However, contrary to our expectations, the IU subfactors did not predict the ERN or posterror slowing (PES), nor did IU and depression interact to predict the ERN. Exploratory analyses also showed that IU did not moderate the relationship between trait anxiety and the ERN; further, IU was not associated with the error positivity (Pe). Overall, our sample shows no evidence for the relationship between intolerance of uncertainty and the registration of errors at the implicit or conscious level (i.e., ERN and Pe, respectively; Hewig et al., 2011). Nevertheless, our findings should not be misinterpreted as conclusive proof of "no effect", but rather considered as a contribution to a small existing literature. Further high-powered replications as well as alternative statistical approaches (e.g., equivalence testing, Bayesian approaches; Harms \& Lakens, 2018) are needed to determine whether the effect of IU on the ERN is meaningful. Moreover, the precise relationship between IU and general performance monitoring may be more nuanced than we have accounted for presently.

Our observation that total IU and the ERN were not associated is in line with Jackson et al. (2016) and Ruchensky et al. (2020). Regarding the additional explanatory value of the IU subfactors compared to the total measure, Jackson et al. (2016) had previously found that the IU subfactors were able to predict the ERN in different directions (i.e., enhanced ERN for 
P-IU; attenuated ERN for I-IU). However, we were not able to replicate this; our null finding instead aligns with two other studies showing no association between the IU subfactors and the error-related negativity (Ruchensky et al., 2020; Sandre \& Weinberg, 2019). A priori power calculations recommended a sample of $n=90$, meaning both Ruchensky et al. (2020; $N=100)$ and the present study $(N=182)$ were adequately powered to detect this association, should it exist. Previous studies with comparatively smaller samples may have run the risk of having spurious findings due to insufficient statistical power (i.e., "false positive"; Button et al., 2013). While further replications are required, the lack of effect of IU subfactors on ERN amplitude suggests that studies previously reporting these associations should be interpreted with caution.

Regarding post-error slowing (PES), we did not replicate the observations of an effect of IU subfactors on post-error RT (Jackson et al., 2016). In their original paper this analysis is referred to as PES, however, this approach does not accurately index PES because it considers post-accuracy RTs (i.e., error and correct responses) separately, rather than a comparison of both in one index (i.e., how much is the next correct trial delayed by a previous mistake compared to the response after a correct trial). Accordingly, two approaches have been defined for calculating PES: (a) PES defined as the difference between average RT after error trials and the average RT after correct trials, and, (b) PES as the mean of the differences from the RT of the correct trial after an error minus the RT of the correct trial before that error (Dutilh et al., 2012; Schroder et al., 2020). In line with Ruchensky et al. (2020), using the former so-called traditional PES, we also obtained a null result, whereby total IU could not predict PES in our sample (Ruchensky et al., 2020). In sum, we did not find evidence for an association of IU and behavioral measures. It is important that studies investigating behavioral adjustments after error commission consider improved estimates of PES to ensure reliability and internal consistency as recommended by Schroder et al. (2020) and Sandre et al. (2020).

Our study also found no relationship between error processing and symptoms of depression or anxiety. We found no main effect of depression on the ERN which is in line with other research showing no relation (Moran et al., 2017; Ruchensky et al., 2020). We also failed to find an association between trait anxiety and the ERN. Previous studies have advanced the ERN as a potential biomarker for anxiety (Meyer, 2016), but the meta-analysis of Saunders and Inzlicht (2020) found that publication bias may have exaggerated the relationship between trait anxiety and the ERN, with no overall correlation for volunteer nonclinical samples. Our null results from a sample of undergraduates support this notion and 
relate to other work that has shown that transdiagnostic anxiety-depression symptom dimensions are not related to ERN magnitude (Seow et al., 2020). While meta-analytic work has shown a small effect for increased ERN amplitude in internalizing disorders (Pasion \& Barbosa, 2019), the effects of attenuated ERNs in externalizing disorders are larger overall (Lutz et al., 2021; Pasion \& Barbosa, 2019). As such, investigations into error processing in externalizing disorders and its relationship to intolerance of uncertainty deserve attention, particularly given findings showing that the desire to remove uncertainty is implicated in impulsive risky behaviors, such as substance abuse (Sadeh \& Bredemeier, 2021).

Based on our lack of direct effects, it was conceivable that the broad measure of total IU might moderate the relationship between depression and the ERN, such that depression and the ERN are only related at low levels of IU (Ruchensky et al., 2020). However, this was not the case for our sample. Moreover, our exploratory analysis showed no interaction between trait anxiety and total IU in explaining the ERN. The fact that total IU or IU subfactors were not associated with symptoms or the ERN/Pe in our models was surprising given that errors have been conceptualized as inherently uncertain threats (Weinberg et al., 2016). Despite our null results, approaching errors as endogenous forms of threat does remain valid, particularly considering the neural and behavioral commonalities shared by errors and exogenous threats (e.g., heightened skin conductance response and pupil dilation, increased amygdala activity; Hajcak \& Foti, 2008; Hajcak et al., 2003; Pourtois et al., 2010). The idea that the IU subfactors should differentially predict ERN amplitudes is elegant because these subfactors capture different ways people respond to unpredictability, either by engaging cognitive control (P-IU) or by inhibition of action (I-IU). However, these constructs overlapped somewhat in our sample $(r=.61)$ which raises questions about their usefulness relative to the total IUS-12 score.

Questions about the validity of the IUS-12 subfactors appear in the extant literature, with support being found for bifactor models with a high loading on a general IU factor (Bottesi et al., 2019; Hale et al., 2016; Lauriola et al., 2016; Shihata et al., 2018; Yao et al., 2021). However other groups have shown discriminant validity for P-IU and I-IU relating to psychopathology (Boelen et al., 2015; McEvoy \& Mahoney, 2011; Penney et al., 2020; Saulnier et al., 2019). While considering the IU subfactors as separate constructs may be useful for distinguishing psychopathology (Penney et al., 2020; Yao et al., 2021), research designs employing additional neural, behavioral and psychophysiological approaches become complex. In particular, associations are harder to find when measurement levels exist at different levels of abstraction (Brandt \& Mueller, 2022), such that trait personality variables 
(e.g., IU) can exist at highly abstracted levels of feeling and behavior and therefore may struggle to predict specific contextualized neurobiological variables (e.g., ERN). Moreover, adjacent research from our lab involving impulsivity has shown that self-report and EEG measurement levels can have within- but not between-level correlations (Bernoster et al., 2019). Consequently, more research is needed before linking IU to ERP measures of neurocognitive processes. Studies which validate the assessment of trait IU via self-report measures as well as other units of analysis should be prioritized, especially with regard to accumulating evidence that the IU subfactors do not link well with the ERN.

Any critique of the IU subfactors is tempered by the fact that total IU was also not a good predictor in the current study: Total IU could not predict the ERN, Pe or Pc. The only significant result in this study was the finding that total IU (but not subfactors) was associated with a larger (i.e., more negative) $\mathrm{CRN}$. This finding is somewhat consistent with a previous study showing that prospective and inhibitory IU were associated with a larger CRN (Sandre \& Weinberg, 2019), although they did not report on total IU. High IU constitutes a risk and maintaining factor for $\mathrm{OCD}$, and a desire to reduce uncertainty may underlie the compulsions in the disorder (particularly repetitive checking behavior; Tolin et al., 2003). Our finding supports the notion of Sandre and Weinberg (2019) that enhanced CRNs may reflect the salience of correctness, and may explain why hypervigilant checking behavior persists despite a registration of having performed correctly. Such associations between IU and the CRN reflect the need for more research and replications in clinical populations, perhaps integrating disorder-specific forms of IU that have been distinguished from dispositional IU (Shihata et al., 2017). Task-elicited uncertainty may also prove relevant given that some conceptualizations of the CRN regard it as sensitive to uncertainty of responses in general, rather than merely indexing commission of correct ones (Pailing \& Segalowitz, 2004). This suggests the CRN could be relevant to performance monitoring under conditions of uncertainty. Along this line Sandre and Weinberg (2019) found relationships between I-IU and flanker trials where correctness was ambiguous. Such adaptions to the flanker task and other paradigms may help understand if the relationship between performance monitoring and IU depends on the task, with the possibility for divergent relations across different forms of psychopathology. As noted by Sandre and Weinberg (2019), it is possible that IU is more related to the recruitment of cognitive control under uncertain conditions, rather than performance monitoring per se.

Our null results were against expectations meaning several general explanations must be considered. Our sample was adequately powered to find a small-to-medium effect if one 
existed, indicating that sample size was not an issue; indeed, this study had almost triple the sample size of Jackson et al. (2016) and Sandre and Weinberg (2019) whom we sought to replicate. Nevertheless, our power was based on effect sizes from published results which may have been exaggerated. The self-report measures employed were reliable, with internal consistency estimates ranging from good to excellent for all measures. Moreover, our data reflected the typical behavioral and electrophysiological patterns expected for a flanker task. The use of the $\triangle E R N$ (i.e., ERN minus CRN) has been criticized because subtraction-based difference scores remain highly correlated with their constituent signals, meaning the $\triangle E R N$ is not independent of the CRN (Meyer et al., 2017). As such, the use of a difference score may not isolate neurophysiological activity specific to error processing and can also lower between-subject variance. Based on this, our analyses were additionally performed using the absolute ERN/Pe (instead of $\Delta \mathrm{ERN} / \Delta \mathrm{Pe}$ ) as a predictor; all effects were all non-significant, suggesting that the use of a difference score did not bear on the null results observed in this study. This approach of comparing different methods of calculating the results is aligned with the objective of the experimental replication (Hudson, 2021), by testing the variables in different but equivalent ways we can ensure that the effects found are there (or not, as in our case), and do not depend on the specific experimenter choice either in design or analysis steps. Finally, our data fulfilled the assumptions for the various statistical tests which points to the robustness of our null results.

\subsection{Limitations}

A couple of limitations of our study need to be mentioned. First, the whole data collection took place during the COVID-19 pandemic, which in itself constitutes a situation of permanent uncertainty. Especially when investigating anxiety-related constructs, we probably need to acknowledge that the lab situation before and during the pandemic cannot be compared. This may be a general issue for clinical research. Second, we used a slightly different experimental design (e.g., letters instead of arrows and faster stimuli presentation) and EEG analysis approach (e.g., EEG signal re-referenced to average instead of mastoids and ERN calculated with single electrode instead of pool of electrodes) compared to the original studies, which however is supported both by previous research using the same experimental design of a flanker task to assess performance monitoring (e.g., Franken et al., 2010) and methodological research testing different analytical pipelines of the flanker task (Sandre et al., 2020). Third, due to the diversity in our sample, we had participants answering the questionnaires in their native language (Dutch, $n=100$ ), while international participants received the questionnaires in English, which for most of them was their second language ( $n$ 
$=82$ ). However, internal consistency in our sample was good for both versions (see table 1 in supplementary material). Fourth, to keep our variables comparable with our reference papers, we did not use a more robust index of the PES. Finally, our models did not account for the strong relationship between IU and worry (which is independent of shared variance with anxiety and depression; Dugas et al., 1997; Freeston et al., 1994), therefore, our results may not represent the unique association between IU and other constructs.

\subsection{Implications and Conclusions}

Altogether, our study shows the need for high-powered replication studies in clinical and individual differences (EEG) research, which is currently underway in different EEG Many Labs replication attempts (Pavlov et al., 2021). Our high-powered replication failure of linking intolerance of uncertainty to an electrophysiological index of error-monitoring underlines the need for further replicability and reproducibility within psychophysiology. Attempts should be made to replicate studies with small samples. Recommendations for transparent and open-science practices in psychophysiology have been discussed extensively elsewhere (Garrett-Ruffin et al., 2021) and will contribute to the viability of replication attempts, while making sure findings are disseminated regardless of statistical significance. In a field that is particularly time- and resource- intensive, efforts are better directed at theorytesting related to uncertainty as opposed to discovery-oriented approaches which run the risk of Type 1 errors and non-replicability (Brandt \& Mueller, 2022). While the ERN and IU have transdiagnostic potential to cut across multiple forms of psychopathology, further rigorous and incremental work is needed to see if, and how, they are related. 


\section{References}

Andreu, C. I., Moënne-Loccoz, C., López, V., Slagter, H. A., Franken, I. H. A., \& Cosmelli, D. (2017). Behavioral and Electrophysiological Evidence of Enhanced Performance Monitoring in Meditators. Mindfulness, 8(6), 1603-1614. https://doi.org/10.1007/s12671-017-0732-z

Beck, A. T., Steer, R. A., \& Brown, G. K. (1996). Manual for the Beck Depression InventoryII. Psychological Corporation.

Bernoster, I., De Groot, K., Wieser, M. J., Thurik, R., \& Franken, I. H. A. (2019). Birds of a feather flock together: Evidence of prominent correlations within but not between selfreport, behavioral, and electrophysiological measures of impulsivity. Biological Psychology, 145(August 2018), 112-123. https://doi.org/10.1016/j.biopsycho.2019.04.008

Boelen, P. A., Reijntjes, A., \& Smid, G. E. (2015). Concurrent and prospective associations of intolerance of uncertainty with symptoms of prolonged grief, posttraumatic stress, and depression after bereavement. Journal of Anxiety Disorders, 41, 65-72. https://doi.org/10.1016/j.janxdis.2016.03.004

Bottesi, G., Noventa, S., Freeston, M. H., \& Ghisi, M. (2019). Seeking certainty about Intolerance of Uncertainty: Addressing old and new issues through the Intolerance of Uncertainty Scale-Revised. PLOS ONE, 14(2), e0211929. https://doi.org/10.1371/JOURNAL.PONE.0211929

Brandt, A., \& Mueller, E. M. (2022). Negative affect related traits and the chasm between self-report and neuroscience. Current Opinion in Behavioral Sciences, 43, 216-223. https://doi.org/10.1016/j.cobeha.2021.11.002

Button, K. S., Ioannidis, J. P. A., Mokrysz, C., Nosek, B. A., Flint, J., Robinson, E. S. J., \& Munafò, M. R. (2013). Power failure: Why small sample size undermines the reliability of neuroscience. Nature Reviews Neuroscience, 14(5), 365-376. 
https://doi.org/10.1038/nrn3475

Carleton, R. N. (2012). The intolerance of uncertainty construct in the context of anxiety disorders: Theoretical and practical perspectives. Expert Review of Neurotherapeutics, 12(8), 937-947. https://doi.org/10.1586/ern.12.82

Carleton, R. N. (2016). Into the unknown: A review and synthesis of contemporary models involving uncertainty. Journal of Anxiety Disorders, 39, 30-43. https://doi.org/10.1016/j.janxdis.2016.02.007

Carleton, R. N., Norton, M. A. P. J., \& Asmundson, G. J. G. (2007). Fearing the unknown: A short version of the Intolerance of Uncertainty Scale. Journal of Anxiety Disorders, 21(1), 105-117. https://doi.org/10.1016/j.janxdis.2006.03.014

Clayson, P. E., Carbine, K. A., Baldwin, S. A., \& Larson, M. J. (2019). Methodological reporting behavior, sample sizes, and statistical power in studies of event-related potentials: Barriers to reproducibility and replicability. Psychophysiology, 56(11), e13437. https://doi.org/10.1111/psyp.13437

Craddock, M. (2016). ERP Visualization Part 1: Comparing two conditions. https://www.mattcraddock.com/blog/2016/09/19/comparing-two-erps/ de Bruin, G. O., Rassin, E., van der Heiden, C., \& Muris, P. (2006). Psychometric properties of a Dutch version of the Intolerance of Uncertainty Scale. Netherlands Journal of Psychology, 62(2), 87-92. https://doi.org/10.1007/bf03061055

Dehaene, S., Posner, M. I., \& Tucker, D. M. (1994). Localization of a neural system for error detection and compensation. Psychological Science, 5(5), 303-305. https://doi.org/10.1111/j.1467-9280.1994.tb00630.x

Does, A. J. W. van der. (2002). BDI-II-NL handleiding : de Nederlandse versie van de Beck depression inventory-second edition. Swets.

Dugas, M. J., Freeston, M. H., \& Ladouceur, R. (1997). Intolerance of uncertainty and 
problem orientation in worry. Cognitive Therapy and Research, 21(6), 593-606. https://doi.org/10.1023/A:1021890322153

Dugas, M. J., Hedayati, M., Karavidas, A., Buhr, K., Francis, K., \& Phillips, N. A. (2005). Intolerance of uncertainty and information processing: Evidence of biased recall and interpretations. Cognitive Therapy and Research, 29(1), 57-70. https://doi.org/10.1007/s10608-005-1648-9

Dutilh, G., Van Ravenzwaaij, D., Nieuwenhuis, S., Van der Maas, H. L. J., Forstmann, B. U., \& Wagenmakers, E. J. (2012). How to measure post-error slowing: A confound and a simple solution. Journal of Mathematical Psychology, 56(3), 208-216. https://doi.org/10.1016/j.jmp.2012.04.001

Endrass, T., Klawohn, J., Schuster, F., \& Kathmann, N. (2008). Overactive performance monitoring in obsessive-compulsive disorder: ERP evidence from correct and erroneous reactions. Neuropsychologia, 46(7), 1877-1887. https://doi.org/10.1016/j.neuropsychologia.2007.12.001

Eriksen, B. A., \& Eriksen, C. W. (1974). Effects of noise letters upon the identification of a target letter in a nonsearch task. Perception \& Psychophysics, 16(1), 143-149. https://doi.org/10.3758/BF03203267

Faul, F., Erdfelder, E., Lang, A. G., \& Buchner, A. (2007). G*Power 3: A flexible statistical power analysis program for the social, behavioral, and biomedical sciences. Behavior Research Methods, 39(2), 175-191. https://doi.org/10.3758/BF03193146

Field, A., Miles, J., \& Field, Z. (2013). Discovering statistics using R. Sage.

Franken, I. H. A., Nijs, I. M. T., Toes, A., \& van der Veen, F. M. (2018). Food addiction is associated with impaired performance monitoring. Biological Psychology, 131, 49-53. https://doi.org/10.1016/j.biopsycho.2016.07.005

Franken, I. H. A., van Strien, J. W., Franzek, E. J., \& van de Wetering, B. J. (2007). Error- 
processing deficits in patients with cocaine dependence. Biological Psychology, 75(1),

Franken, I. H. A., van Strien, J. W., \& Kuijpers, I. (2010). Evidence for a deficit in the salience attribution to errors in smokers. Drug and Alcohol Dependence, 106(2), 181185. https://doi.org/10.1016/j.drugalcdep.2009.08.014

Freeston, M. H., Rhéaume, J., Letarte, H., Dugas, M. J., \& Ladouceur, R. (1994). Why do people worry? Personality and Individual Differences, 17(6), 791-802. https://doi.org/10.1016/0191-8869(94)90048-5

Garrett-Ruffin, S., Hindash, A. C., Kaczkurkin, A. N., Mears, R. P., Morales, S., Paul, K., Pavlov, Y. G., \& Keil, A. (2021). Open science in psychophysiology: An overview of challenges and emerging solutions. International Journal of Psychophysiology, 162(September 2020), 69-78. https://doi.org/10.1016/j.ijpsycho.2021.02.005

Gehring, W. J., Goss, B., Coles, M. G. H., Meyer, D. E., \& Donchin, E. (1993). A Neural System for Error Detection and Compensation. Psychological Science, 4(6), 385-390. https://doi.org/10.1111/j.1467-9280.1993.tb00586.x

Gratton, G., Coles, M. G. H., \& Donchin, E. (1983). A new method for off-line removal of ocular artifact. Electroencephalography and Clinical Neurophysiology, 55(4), 468-484. https://doi.org/10.1016/0013-4694(83)90135-9

Hajcak, G., \& Foti, D. (2008). Errors are aversive: Defensive motivation and the error-related negativity: Research report. Psychological Science, 19(2), 103-108. https://doi.org/10.1111/j.1467-9280.2008.02053.x

Hajcak, G., McDonald, N., \& Simons, R. F. (2003). To err is autonomic: Error-related brain potentials, ANS activity, and post-error compensatory behavior. Psychophysiology, 40(6), 895-903. https://doi.org/10.1111/1469-8986.00107

Hale, W., Richmond, M., Bennett, J., Berzins, T., Fields, A., Weber, D., Beck, M., \& Osman, 
A. (2016). Resolving Uncertainty About the Intolerance of Uncertainty Scale-12: Application of Modern Psychometric Strategies. Journal of Personality Assessment, 98(2), 200. https://doi.org/10.1080/00223891.2015.1070355

Harms, C., \& Lakens, D. (2018). Making "null effects" informative: statistical techniques and inferential frameworks. Journal of Clinical and Translational Research, 3, 382-393. https://doi.org/10.18053/jctres.03.2017s2.007

Hewig, J., Coles, M. G. H., Trippe, R. H., Hecht, H., \& Miltner, W. H. R. (2011). Dissociation of Pe and ERN/Ne in the conscious recognition of an error. Psychophysiology, 48(10), 1390-1396. https://doi.org/10.1111/j.14698986.2011.01209.x

Hoffmann, S., \& Falkenstein, M. (2012). Predictive information processing in the brain: Errors and response monitoring. International Journal of Psychophysiology, 83(2), 208212. https://doi.org/10.1016/j.ijpsycho.2011.11.015

Holmes, A. J., \& Pizzagalli, D. A. (2008). Spatiotemporal dynamics of error processing dysfunctions in major depressive disorder. Archives of General Psychiatry, 65(2), 179188. https://doi.org/10.1001/archgenpsychiatry.2007.19

Hudson, R. (2021). Explicating Exact versus Conceptual Replication. Erkenntnis, 0123456789. https://doi.org/10.1007/s10670-021-00464-z

Jackson, F., Nelson, B. D., \& Hajcak, G. (2016). The uncertainty of errors: Intolerance of uncertainty is associated with error-related brain activity. Biological Psychology, 113, 52-58. https://doi.org/10.1016/j.biopsycho.2015.11.007

Larson, M. J., \& Carbine, K. A. (2017). Sample size calculations in human electrophysiology (EEG and ERP) studies: A systematic review and recommendations for increased rigor. International Journal of Psychophysiology, 111, 33-41. https://doi.org/10.1016/j.ijpsycho.2016.06.015 
Lauriola, M., Mosca, O., \& Carleton, R. N. (2016). Hierarchical factor structure of the Intolerance of Uncertainty Scale short form (IUS-12) in the Italian version. TPMTesting, Psychometrics, Methodology in Applied Psychology, 23(3), 377-394.

Liao, K. Y. H., \& Wei, M. (2011). Intolerance of uncertainty, depression, and anxiety: The moderating and mediating roles of rumination. Journal of Clinical Psychology, 67(12), 1220-1239. https://doi.org/10.1002/jclp.20846

Long, J. A. (2020). jtools: Analysis and Presentation of Social Scientific Data. (R package version 2.1.0). https://cran.r-project.org/package=jtools

Lutz, M. C., Kok, R., Verveer, I., Malbec, M., Koot, S., van Lier, P. A. C., \& Franken, I. H. A. (2021). Diminished error-related negativity and error positivity in children and adults with externalizing problems and disorders: A meta-analysis on error processing. Journal of Psychiatry and Neuroscience, 46(6), E615-E627. https://doi.org/10.1503/jpn.200031

Mahoney, A. E. J., \& McEvoy, P. M. (2012). Trait Versus Situation-Specific Intolerance of Uncertainty in a Clinical Sample with Anxiety and Depressive Disorders. Cognitive Behaviour Therapy, 41(1), 26-39. https://doi.org/10.1080/16506073.2011.622131

McEvoy, P. M., Hyett, M. P., Shihata, S., Price, J. E., \& Strachan, L. (2019). The impact of methodological and measurement factors on transdiagnostic associations with intolerance of uncertainty: A meta-analysis. Clinical Psychology Review, 73, 101778. https://doi.org/10.1016/j.cpr.2019.101778

McEvoy, P. M., \& Mahoney, A. E. J. (2011). Achieving certainty about the structure of intolerance of uncertainty in a treatment-seeking sample with anxiety and depression. Journal of Anxiety Disorders, 25(1), 112-122. https://doi.org/10.1016/j.janxdis.2010.08.010

Meyer, A. (2016). Developing Psychiatric Biomarkers: a Review Focusing on the ErrorRelated Negativity as a Biomarker for Anxiety. Current Treatment Options in 
Psychiatry, 3(4), 356-364. https://doi.org/10.1007/s40501-016-0094-5

Meyer, A., Lerner, M. D., De Los Reyes, A., Laird, R. D., \& Hajcak, G. (2017). Considering ERP difference scores as individual difference measures: Issues with subtraction and alternative approaches. Psychophysiology, 54(1), 114-122. https://doi.org/10.1111/psyp.12664

Meyer, T. J., Miller, M. L., Metzger, R. L., \& Borkovec, T. D. (1990). Development and validation of the penn state worry questionnaire. Behaviour Research and Therapy, 28(6), 487-495. https://doi.org/10.1016/0005-7967(90)90135-6

Moran, T. P., Schroder, H. S., Kneip, C., \& Moser, J. S. (2017). Meta-analysis and psychophysiology: A tutorial using depression and action-monitoring event-related potentials. International Journal of Psychophysiology, 111, 17-32. https://doi.org/10.1016/j.ijpsycho.2016.07.001

Moser, J. S., Moran, T. P., Schroder, H. S., Donnellan, M. B., \& Yeung, N. (2013). On the relationship between anxiety and error monitoring: A meta-analysis and conceptual framework. Frontiers in Human Neuroscience, 7, 466. https://doi.org/10.3389/fnhum.2013.00466

Olvet, D. M., \& Hajcak, G. (2009). The stability of error-related brain activity with increasing trials. Psychophysiology, 46(5), 957-961. https://doi.org/10.1111/j.14698986.2009.00848.x

Pailing, P. E., \& Segalowitz, S. J. (2004). The error-related negativity as a state and trait measure: Motivation, personality, and ERPs in response to errors. Psychophysiology, 41(1), 84-95. https://doi.org/10.1111/1469-8986.00124

Pasion, R., \& Barbosa, F. (2019). ERN as a transdiagnostic marker of the internalizingexternalizing spectrum: A dissociable meta-analytic effect. Neuroscience and Biobehavioral Reviews, 103(May), 133-149. 
https://doi.org/10.1016/j.neubiorev.2019.06.013

Pavlov, Y. G., Adamian, N., Appelhoff, S., Arvaneh, M., Benwell, C. S. Y., Beste, C., Bland, A. R., Bradford, D. E., Bublatzky, F., Busch, N. A., Clayson, P. E., Cruse, D., Czeszumski, A., Dreber, A., Dumas, G., Ehinger, B., Ganis, G., He, X., Hinojosa, J. A., ... Mushtaq, F. (2021). \#EEGManyLabs: Investigating the replicability of influential EEG experiments. Cortex. https://doi.org/10.1016/J.CORTEX.2021.03.013

Penney, A. M., Rachor, G. S., \& Deleurme, K. A. (2020). Differentiating the roles of intolerance of uncertainty and negative beliefs about worry across emotional disorders. Journal of Experimental Psychopathology, 11(4), 1-22. https://doi.org/10.1177/2043808720970072

Ploeg, H. M. v.d. (2000). Handleiding bij de Zelf Beoordelings Vragenlijst, ZBV. (2e gewijzi). Swets \& Zeitlinger.

Pourtois, G., Vocat, R., N'Diaye, K., Spinelli, L., Seeck, M., \& Vuilleumier, P. (2010). Errors recruit both cognitive and emotional monitoring systems: Simultaneous intracranial recordings in the dorsal anterior cingulate gyrus and amygdala combined with fMRI. Neuropsychologia, 48(4), 1144-1159. https://doi.org/10.1016/j.neuropsychologia.2009.12.020

Proudfit, G. H., Inzlicht, M., \& Mennin, D. S. (2013). Anxiety and error monitoring: The importance of motivation and emotion. Frontiers in Human Neuroscience, 7, 636. https://doi.org/10.3389/fnhum.2013.00636

R Core Team. (2021). R: A language and environment for statistical computing. $\mathrm{R}$ Foundation for Statistical Computing. www.r-project.org

Ruchensky, J. R., Bauer, E. A., \& MacNamara, A. (2020). Intolerance of uncertainty, depression and the error-related negativity. International Journal of Psychophysiology, 153(April 2019), 45-52. https://doi.org/10.1016/j.ijpsycho.2020.04.015 
Sadeh, N., \& Bredemeier, K. (2021). Engaging in risky and impulsive behaviors to alleviate distress mediates associations between intolerance of uncertainty and externalizing psychopathology. Journal of Personality Disorders, 35(3), 393-408. https://doi.org/10.1521/pedi_2019_33_456

Sandre, A., Banica, I., Riesel, A., Flake, J., Klawohn, J., \& Weinberg, A. (2020). Comparing the effects of different methodological decisions on the error-related negativity and its association with behaviour and gender. International Journal of Psychophysiology, 156, 18-39. https://doi.org/10.1016/J.IJPSYCHO.2020.06.016

Sandre, A., \& Weinberg, A. (2019). Neither wrong nor right: Theta and delta power increase during performance monitoring under conditions of uncertainty. International Journal of Psychophysiology, 146(September), 225-239. https://doi.org/10.1016/j.ijpsycho.2019.09.015

Saulnier, K. G., Allan, N. P., Raines, A. M., \& Schmidt, N. B. (2019). Depression and Intolerance of Uncertainty: Relations between Uncertainty Subfactors and Depression Dimensions. Psychiatry, 82(1), 72-79. https://doi.org/10.1080/00332747.2018.1560583

Saunders, B., \& Inzlicht, M. (2020). Assessing and adjusting for publication bias in the relationship between anxiety and the error-related negativity. International Journal of Psychophysiology, 155, 87-98. https://doi.org/10.1016/j.ijpsycho.2020.05.008

Schroder, H. S., Nickels, S., Cardenas, E., Breiger, M., Perlo, S., \& Pizzagalli, D. A. (2020). Optimizing assessments of post-error slowing: A neurobehavioral investigation of a flanker task. Psychophysiology, 57(2), e13473. https://doi.org/10.1111/psyp.13473

Seow, T. X. F., Benoit, E., Dempsey, C., Jennings, M., Maxwell, A., McDonough, M., \& Gillan, C. M. (2020). A dimensional investigation of error-related negativity (ERN) and self-reported psychiatric symptoms. International Journal of Psychophysiology, 158(October), 340-348. https://doi.org/10.1016/j.ijpsycho.2020.09.019 
Shihata, S., McEvoy, P. M., \& Mullan, B. A. (2017). Pathways from uncertainty to anxiety: An evaluation of a hierarchical model of trait and disorder-specific intolerance of uncertainty on anxiety disorder symptoms. Journal of Anxiety Disorders, 45, 72-79. https://doi.org/10.1016/j.janxdis.2016.12.001

Shihata, S., McEvoy, P. M., \& Mullan, B. A. (2018). A bifactor model of intolerance of uncertainty in undergraduate and clinical samples: Do we need to reconsider the twofactor model? In Psychological Assessment (Vol. 30, Issue 7, pp. 893-903). American Psychological Association. https://doi.org/10.1037/pas0000540

Spielberger, C. D. (1983). Manual for the State-Trait Anxiety Inventory STAI (Form Y). Mind Garden.

Tolin, D. F., Abramowitz, J. S., Brigidi, B. D., \& Foa, E. B. (2003). Intolerance of uncertainty in obsessive-compulsive disorder. Journal of Anxiety Disorders, 17(2), 233242. https://doi.org/10.1016/S0887-6185(02)00182-2

Van Rijsoort, S., Emmelkamp, P., \& Vervaeke, G. (1999). Assessment the Penn State Worry Questionnaire and the Worry Domains Questionnaire: Structure, reliability and validity. Clinical Psychology and Psychotherapy, 6(4), 297-307. https://doi.org/10.1002/(SICI)1099-0879(199910)6:4<297::AID-CPP206>3.0.CO;2-E

Weinberg, A., Dieterich, R., \& Riesel, A. (2015). Error-related brain activity in the age of RDoC: A review of the literature. International Journal of Psychophysiology, 98(2), 276-299. https://doi.org/10.1016/j.ijpsycho.2015.02.029

Weinberg, A., Klein, D. N., \& Hajcak, G. (2012). Increased error-related brain activity distinguishes generalized anxiety disorder with and without comorbid major depressive disorder. Journal of Abnormal Psychology, 121(4), 885-896.

https://doi.org/10.1037/a0028270

Weinberg, A., Kotov, R., \& Proudfit, G. H. (2015). Neural indicators of error processing in 
generalized anxiety disorder, obsessive-compulsive disorder, and major depressive disorder. Journal of Abnormal Psychology, 124(1), 172-185.

https://doi.org/10.1037/abn0000019

Weinberg, A., Meyer, A., Hale-Rude, E., Perlman, G., Kotov, R., Klein, D. N., \& Hajcak, G. (2016). Error-related negativity (ERN) and sustained threat: Conceptual framework and empirical evaluation in an adolescent sample. Psychophysiology, 53(3), 372-385. https://doi.org/10.1111/psyp.12538

Weinberg, A., Olvet, D. M., \& Hajcak, G. (2010). Increased error-related brain activity in generalized anxiety disorder. Biological Psychology, 85(3), 472-480.

https://doi.org/10.1016/j.biopsycho.2010.09.011

Wickham, H. (2016). ggplot2: Elegant Graphics for Data Analysis. Springer-Verlag New York. https://ggplot2.tidyverse.org

Yao, N., Qian, M., Jiang, Y., \& Elhai, J. D. (2021). The Influence of Intolerance of Uncertainty on Anxiety and Depression Symptoms in Chinese-speaking Samples: Structure and Validity of The Chinese Translation of The Intolerance of Uncertainty Scale. Journal of Personality Assessment, 103(3), 406-415. https://doi.org/10.1080/00223891.2020.1739058

Zijlmans, J., Marhe, R., Bevaart, F., Van Duin, L., Luijks, M. J. A., Franken, I., Tiemeier, H., \& Popma, A. (2021). The predictive value of neurobiological measures for recidivism in delinquent male young adults. Journal of Psychiatry and Neuroscience, 46(2), E271E280. https://doi.org/10.1503/jpn.200103 


\section{Acknowledgments}

Marcelo Malbec was supported by a doctoral scholarship granted by CONICYT, the National Commission for Scientific and Technological Research of Chile (2018/72190432) during preparation of this manuscript.

The authors would like to thank Idil Erpolat, Fay Savvopoulou and Mariam Beriashvili for their valuable help in data collection. Special thanks to Karla Knežević, who also collected data and helped with the lab coordination. Thanks to Andre Mamede and Asimina Aslanidou for their comments on the methods.

The authors would also thank the whole staff at the Erasmus Behavioral Lab for continuous support, especially Christiaan Tieman for his valuable help in programming and EEG equipment testing. 


\section{Supplementary material}

\section{Supplement A: Results of assumption testing plots}

As per Field et al. (2013), the assumptions for multiple linear regression were tested, including linearity (Residuals vs Fitted in Figure A1-A4), normality (Normal Q-Q in Figure A1-A4) and homoscedasticity (Scale-Location in Figure A1-A4). No violations were detected for any regression anlayses (Hypothesis 1,2,3) or the moderation analysis (Hypothesis 4). Multicolinearity was tested based on the prescence of correlations above $r>.80$ (see Results Table 3), and was also not an issue.

\section{Figure A1}
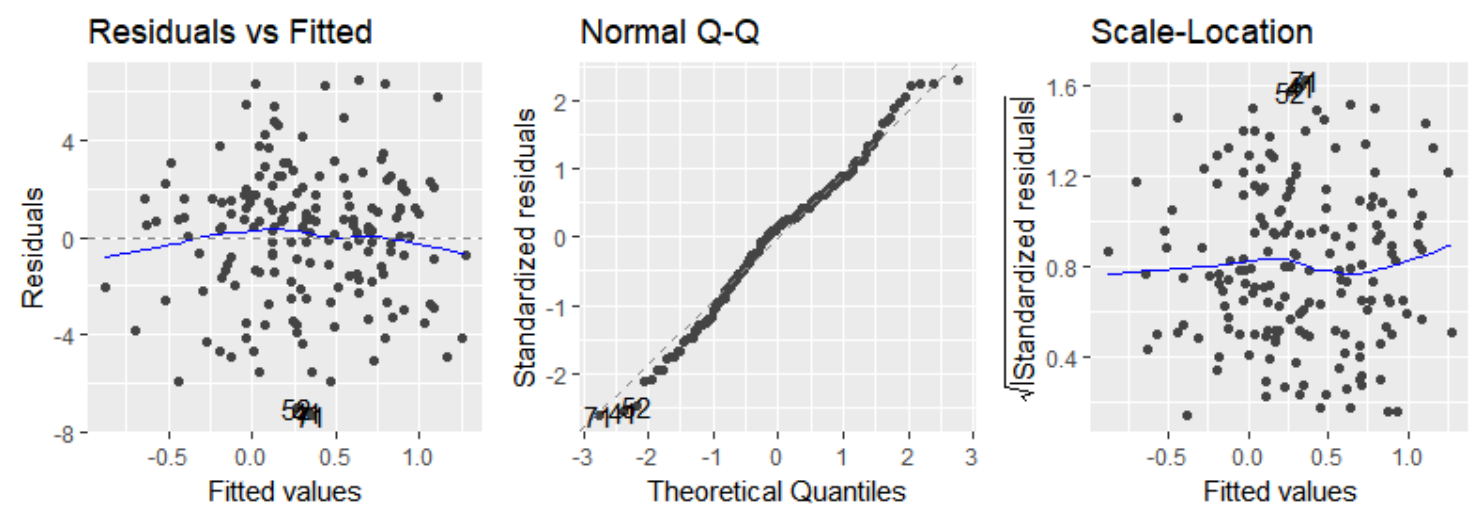

Figure A1. Assumption testing plots for relationship between IU subtypes and ERN amplitude (H1). No assumptions violated. 
Figure A2
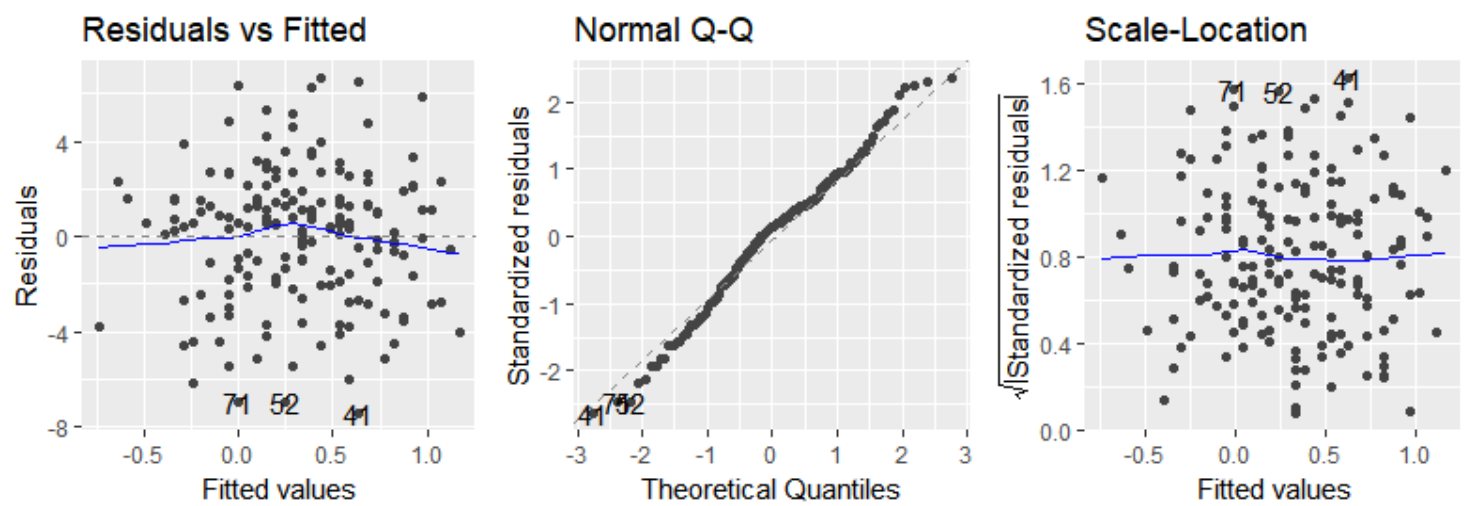

Figure A2. Assumption testing plots for relationship between total IU and ERN amplitude (H2). No violations.

\section{Figure A3}
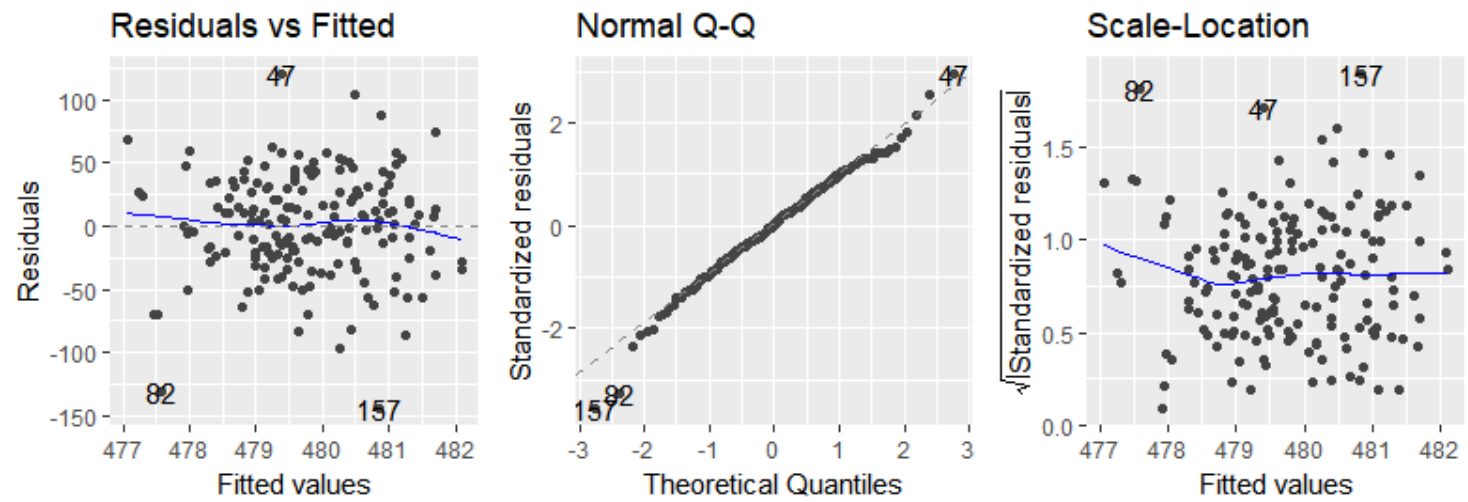

Figure A3. Assumption testing plots for relationship between Total IU and Post-Error slowing (H3). No violations. 
Figure A4
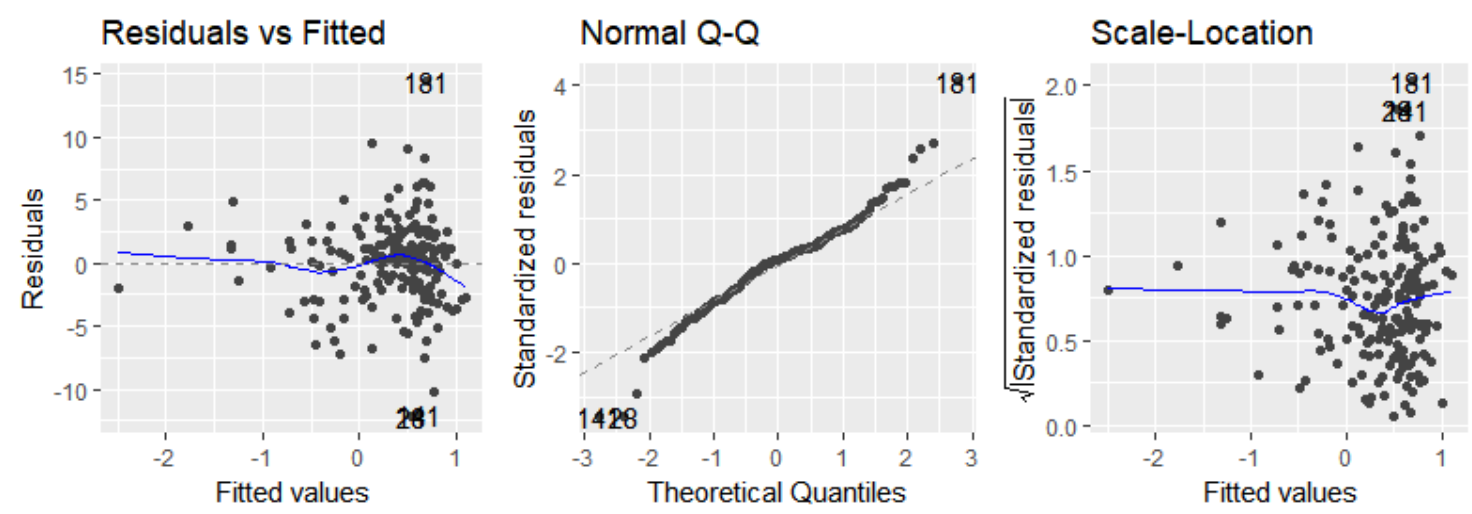

Figure A4. Assumption testing plots for depression predicting $\triangle \mathrm{ERN}$ as moderated by IU (H4). No violations observed. 
Supplement B: Internal consistency results for questionnaires by language

Table B1

Internal consistency of questionnaires by language

\begin{tabular}{lccc}
\hline Questionnaire & Dutch $\alpha$ & English $\alpha$ & Total $\alpha$ \\
\hline IUS-12 & .79 & .90 & .86 \\
P-IU & .73 & .86 & .81 \\
I-IU & .68 & .83 & .76 \\
BDI-II & .94 & .94 & .94 \\
STAI-T & .72 & .85 & .76 \\
PSWQ & .85 & .81 & .83 \\
\hline
\end{tabular}

Note. Total $\mathrm{N}=182$. Dutch $n=100$. English $n=82 . \alpha=$ Cronbach's alpha. IUS- $12=$ Intolerance of Uncertainty, Short Form; P-IU = Prospective intolerance of uncertainty; I$\mathrm{IU}=$ Inhibitory intolerance of uncertainty; STAI-T $=$ trait subscale of the State Trait Anxiety Inventory; BDI-II = Beck Depression Inventory, Second Edition; PSWQ = Penn State Worry Questionnaire 
Supplement C: Moderation analyses performed with ERN

\section{Table C1}

Standardized beta coefficients ( $\beta$ ) for regression analyses predicting the ERN

\begin{tabular}{lccc}
\hline & Model 1 & Model 2 & Model 3 \\
\hline Predictors (Depression) & & & -0.01 \\
Depression & -0.02 & -0.01 & -0.05 \\
Total IU & -0.05 & -0.05 & $<-0.01$ \\
Depression $\times$ IU & & & \\
& & & \\
Predictors (Trait Anxiety) & & -0.03 & -0.03 \\
Trait Anxiety & -0.04 & -0.04 & -0.04 \\
Total IU & -0.05 & & $<-0.01$ \\
Trait Anxiety $\times$ IU & & &
\end{tabular}

Note. $N=182$. Model 1 = separate predictors; model $2=$ simultaneous predictors; model $3=$ simultaneous predictors plus interaction term. No coefficients were significant at $p<.005$. 